This item was submitted to Loughborough's Institutional Repository (https://dspace.lboro.ac.uk/) by the author and is made available under the following Creative Commons Licence conditions.

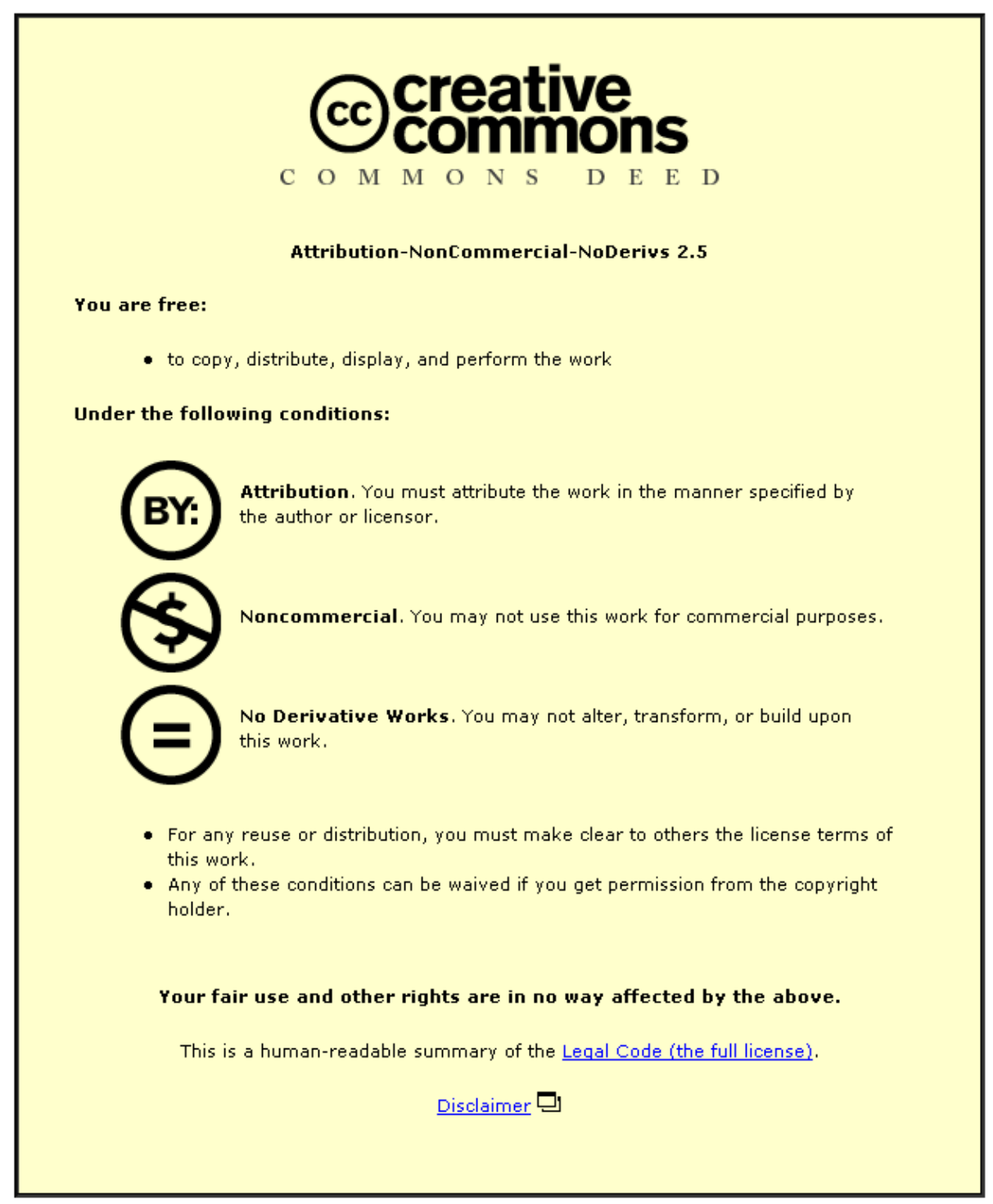

For the full text of this licence, please go to: http://creativecommons.org/licenses/by-nc-nd/2.5/ 


\title{
Contamination of Indoor Air by Toxic Soil Vapours: The Effects of Subfloor Ventilation and Other Protective Measures
}

\author{
V.V. KRYLOV and C. C. FERGUSON \\ Centre for Research into the Built Environment \\ The Nottingham Trent University, \\ Burton Street, Nottingham NG1 4BU, U.K.
}

\begin{abstract}
A steady-state analytical model is derived for estimating the concentration of vapour-phase contaminants in indoor air in houses with subfloor voids, given the contaminant concentration in bulk soil. The model includes the key mechanisms of transport and dispersion - contaminant partitioning into the soil-vapour phase, molecular diffusion, suction flow, stack effect, and ventilation, including contaminant transport by ventilation flow between subfloor void and living space. Using the model, different construction styles are examined from the point of view of their resistance to ingress of soil gases. Model results indicate that indoor air concentration depends strongly on wind velocity and on geometrical parameters of void and living space. Worked examples for houses of different construction styles illustrate the effects of wind velocity and house parameters on the concentration of benzene in soil that would give rise to its maximum permissible concentration in indoor air. Brief consideration is also given to concrete raft foundations and clean cover systems.
\end{abstract}




\section{INTRODUCTION}

The increased use of brownfield sites for housing emphasises the need for rigorous assessment of human health risks from soil contaminants. Under certain circumstances soil vapours migrating into the living spaces of houses may reach concentrations that could be harmful to human health. Indeed, for some volatile organic compounds this may be the dominant pathway from source (contaminated soil) to target (the occupants of a house). To take such hazards into account, housebuilders need reliable guidance when developing brownfield sites. This paper provides a theoretical basis for developing such guidance for houses constructed with a subfloor void. It complements earlier work relating to houses constructed with a ground-bearing concrete slab [1,2].

Predictions of the indoor air concentration of volatile contaminants derived from soil depend strongly on the structural form of a house and the local weather conditions. The model developed by Nazaroff et al [3] in the context of radon transport is specific to a particular style of North American house construction with basement sump and perimeter drain-tile system. The model developed by Ferguson et al. [2] is specific to the ground-bearing slab foundation of new-estate detached housing in the U.K. However, these structural forms represent only a small fraction of existing and new-build housing in the U.K. The aim of the present study is to extend the approach developed in [2] to describe the equilibrium concentration of volatile contaminants in indoor air in some typical variations of U.K. houses constructed with subfloor voids (Fig. 1).

In the following sections we consider the key mechanisms of contaminant transport and dispersion - contaminant partitioning into the soil-vapour phase, molecular diffusion, suction flow, stack effect, and ventilation - with emphasis on the peculiarities of ventilation processes associated with the presence of a subfloor void. We derive a general analytical expression for 
the permissible contaminant concentration in soil that would give rise to a given "safe" concentration in indoor air averaged over a life time. Worked examples illustrate the influence of wind velocity and different house parameters on the maximum permissible concentration of benzene in soil, i.e. that which would give rise to a given benzene concentration in indoor air related to a certain Air Quality Standard.

\section{PARTITIONING OF CONTAMINANTS INTO THE SOIL-VAPOUR PHASE}

Partitioning of organic contaminants between the solid, liquid and gaseous phases of soil is controlled by vapour pressure and aqueous solubility of the contaminant (or their ratio, which is Henry's Law constant) and by the partition coefficient between soil organic carbon and water, $K_{O C}$. The equilibrium contaminant concentration in the vapour phase, $C_{V}\left[\mu \mathrm{g} / \mathrm{cm}^{3}\right]$, is given by the simple equation (see, e.g., [2])

$$
C_{V}=K_{b} C_{b}
$$

where

$$
K_{b}=\left[\left(K_{O C} \cdot f_{o C}\right) / H^{\prime}+S_{w} / \gamma H^{\prime}+S_{a} / \gamma\right]^{-1} \text {. }
$$

Here $C_{b}[\mu \mathrm{g} / \mathrm{g}]$ is the contaminant concentration in bulk soil (reported according to the standard dry weight convention), $H^{\prime}$ is the dimensionless Henry's constant (see [4] for values of $H^{\prime}$ for many organic contaminants), $f_{O C}$ is the organic carbon fraction in soil, $\gamma$ is the specific gravity of the bulk (dry) soil, and $S_{W}$ and $S_{a}$ are, respectively, the water-filled and air-filled porosities of the soil.

\section{MOLECULAR DIFFUSION}

In the problem being considered diffusive fluxes are described using the well-known linear relations

$$
q_{i j}=D_{i j}\left(C_{i}-C_{j}\right)
$$


where $q_{i j}$ is the flux $\left[\mathrm{g} / \mathrm{m}^{2} \mathrm{~h}\right]$ from compartment $i$ to compartment $j$. In the model of a house with a subfloor void (Fig. 1) $i$ and $j$ take values $0,1,2$ or 3 denoting the following compartments:

$0 \quad$ : soil

1 : subfloor void

2 : living space

3 : outdoor space

Contaminant vapour concentration in the relevant compartment is denoted $C_{i}$ or $C_{j}\left[\mathrm{~g} / \mathrm{m}^{3}\right]$, and the $D_{i j}$ are the coefficients of molecular diffusion $[\mathrm{m} / \mathrm{h}]$ for the material layers (ground surface, floor, wall or ceiling) separating the relevant compartments. In what follows we will set the concentration of contaminant in the soil-vapour, $C_{0}$, equal to $C_{V}$ as calculated in equation (1). We now consider the diffusion coefficients in more detail.

\section{Diffusion through the ground surface}

Two basic construction details are considered. The first assumes a ground surface covered by hard core $(h c)$, blinding sand (bs), and oversite concrete (oc) beneath a suspended timber floor (Fig. 2a). The second assumes a ground surface covered by hard core and blinding sand beneath a proprietary beam and block floor system (Fig. 2b). For both these cases the diffusion coefficient controlling diffusive flux from soil to subfloor void, $D_{01}$, is calculated from the component diffusion coefficients identified by the above subscripts,

$$
1 / D_{01}=1 / D_{h c}+1 / D_{b s}+1 / D_{o c}
$$

where the option of removing oversite concrete may be realised by setting $1 / D_{o c}$ equal to zero. Each component coefficient is calculated as the effective molecular diffusivity $D_{\text {eff }}$ of 
the contaminant in the relevant material $\left[\mathrm{m}^{2} / \mathrm{h}\right]$, divided by the corresponding layer thickness $d_{l}[m]$.

For hard core, blinding sand, and oversite concrete the effective molecular diffusivity $D_{\text {eff }}$ is controlled by porosity of the medium. According to Thibodeaux \& Scott [5], it is described by the equation

$$
D_{e f f}=D_{a} \frac{S_{a}^{10 / 3}}{S_{t}^{2}},
$$

where $D_{a}$ is the molecular diffusivity in air, $S_{a}$ is the air-filled porosity and $S_{t}$ is the total porosity (both in percent) of the medium. Calculations using (3) and (4) show that, for typical values of porosity and thickness, the coefficient $D_{01}$ for a subfloor with oversite concrete (Fig. 2a) has a value of about $5 \times 10^{-4} \mathrm{~m} / \mathrm{h}$ which is largely determined by the oversite concrete layer. In the absence of oversite concrete (Fig. 2b) the coefficient $D_{01}$ is much larger, about $7 \times 10^{-3} \mathrm{~m} / \mathrm{h}$.

\section{Diffusion through the floor}

We consider two typical floor constructions above a void. The first comprises a fibre insulation layer (il) and suspended timber floor ( $t$ ) (Fig. 2a). The second consists of a proprietary beam and block floor system (bf) with screed (s), insulation layer (il), a PVC damp-proof membrane ( $d p)$ and wooden decking ( $w)$ (Fig. 2b).

The diffusion coefficient controlling diffusive flux from subfloor void to a living space, $D_{12}$, is thus calculated from the component diffusion coefficients identified by the above subscripts:

1. For the first construction 


$$
1 / D_{12}=1 / D_{i l}+1 / D_{t f}
$$

2. For the second construction

$$
1 / D_{12}=1 / D_{b f}+1 / D_{s}+1 / D_{i l}+1 / D_{d p}+1 / D_{w}
$$

Each component coefficient in (5) and (6) is calculated as the effective molecular diffusivity $D_{\text {eff }}$ of the contaminant in the relevant material $\left[\mathrm{m}^{2} / \mathrm{h}\right]$, divided by the layer thickness $d_{l}[\mathrm{~m}]$. We consider proprietary beam and block floor systems as well as wooden decking to be perfectly penetrable $\left(1 / D_{b f}=0\right.$ and $1 / D_{w}=0$ respectively). A very carefully laid and sealed PVC damp-proof layer is probably a rather efficient barrier. In practice, however, its effective diffusivity is controlled by gaps, tears and puncture holes. We take the view that, for assessing long term exposure to contaminant vapours, it would be prudent to treat this layer as very leaky $\left(1 / D_{d p} \approx 0\right)$.

For the other materials, effective molecular diffusivity $D_{\text {eff }}$ is controlled by porosity of the medium (Table 1). The presence of small gaps in a timber floor, e.g. between floorboards, will be taken into account later via ventilation flow between void and living space. Calculations using (4) - (6) show that, for typical values of porosity and thickness, the coefficient $D_{12}$ has a value of about $6 \times 10^{-2} \mathrm{~m} / \mathrm{h}$ for suspended timber floors, and about $2 \times 10^{-2} \mathrm{~m} / \mathrm{h}$ for beam and block floors.

\section{Diffusion through walls and ceiling}

For walls and ceiling, the diffusion coefficients are the same as in the ground-bearing slab model considered in an earlier paper [2]. We assume that house walls are constructed of a five-layer sandwich of brick (b), air gap (ag), insulating layer (il), lightweight block (lb), and surface coating (sc). As before, the overall diffusion coefficient for the wall, $D_{23(w)}$, is determined by the components. Thus, neglecting the air gap where convection processes prevail, we have: 


$$
1 / D_{23(w)}=1 / D_{b}+1 / D_{i l}+1 / D_{l b}+1 / D_{S C}
$$

Again, for typical values it is easy to show that the overall coefficient $D_{23}$ is largely determined by the brick layer. Coefficient of diffusion through the ceiling, $D_{23(c)}$, is calculated similarly but with a three layer sandwich - surface coating, plaster board, insulating layer:

$$
1 / D_{23(c)}=1 / D_{S C}+1 / D_{p b}+1 / D_{i l}
$$

It is assumed that there is no effective diffusion barrier between the roof space and outside air, and hence the roof space is treated as part of the outside air (Fig. 1).

\section{VENTILATION}

In houses constructed with a ground-bearing slab foundation natural ventilation takes place in a single volume (living space). To describe the influence of ventilation on indoor air quality in such houses it is normally sufficient to use a single parameter, the air exchange rate for all the house. For houses with subfloor voids one has to consider two separate volumes, the living space and the subfloor void. Therefore, to calculate all ventilation fluxes inside the house it is necessary to analyse a more complex aerodynamic problem taking into account a vertical profile of wind velocity over the ground surface. This allows estimation of the pressure differences between outside and inside air separately for living space and void. In addition, one can determine the aerodynamic pressure difference between void and living space. In winter, the contribution of a stack pressure, which occurs due to the temperature difference between indoor and outdoor air, should be added to the aerodynamic pressure difference. The resulting air fluxes between the various compartments can be calculated using wall, floor and ground structure resistances to air flow which link the averaged air velocities to the corresponding pressure drops. 
Detailed investigation into the ventilation performance of houses with voids is possible using the BREVENT computer model developed by the Building Research Establishment, which allows numerical calculation of all aerodynamic pressures and resulting fluxes [6]. However, for the purpose of calculating indoor air quality as part of a probabilistic screening risk assessment for potentially contaminated sites, it is important to develop a simplified analytical model of ventilation which nevertheless reflects all important features of the process. Such a model is developed below.

Wind velocity profile over the ground surface.

There are different mathematical models describing experimentally observed vertical profiles of wind velocity over the ground surface. The simplest one is the power-law profile describing wind speed $v$ at height $H$ above the ground surface according to the formula [7]:

$$
v=v_{0}\left(H / H_{0}\right)^{\alpha}
$$

Here $H_{0}$ is the reference height (usually $H_{0}=10 \mathrm{~m}$ ), and $v_{0}$ is the wind velocity at $H=H_{0}$; $\alpha$ is the exponent which takes values 0.17 (open flat spaces), 0.20 (countryside with occasional obstacles), 0.25 (built up areas) or 0.33 (city areas) [7].

\section{Wind-induced pressure}

The dynamic air pressure associated with wind acting on house walls may be evaluated as

$$
P=1 / 2 \rho v^{2} k
$$


where $\rho$ is the mass density of outdoor air; $k$ is a position-dependent coefficient in the range -1 to +1 which describes the distribution of wind-induced pressure over house walls. Positive values of $k$ relate to the windward side of a house (which we will call the front wall) and describe air compression; negative values of $k$ occur at the roof, rear and side walls of a house, corresponding to suction [8,9]. For our purposes it is adequate to consider a simplified one-dimensional picture of dynamic pressure distribution assuming that pressure (eqn (10)) is applied only to the front and rear walls characterised respectively by the averaged coefficients $k=k_{f}$ and $k=k_{r}$. Using typical experimental data obtained in a wind tunnel [8], and averaging positive pressure coefficients over the front wall and negative pressure coefficients over the two side walls and the rear wall, we obtain: $k_{f}=0.915$ and $k_{r}=-0.8$.

\section{Floor and wall resistance to air flow}

The velocity of air flow penetrating through artificial openings or through natural gaps and cracks depends on the pressure drop across the barrier and on size of openings. For small cracks and gaps and moderate pressure drops, which are typical conditions for a house floor, the role of air viscosity is dominant and the air flow is mainly laminar. The velocity of air $v$ $[\mathrm{m} / \mathrm{h}]$ driven through such a cracked and porous medium by a pressure gradient $D \mathrm{P}$ may be described by Darcy's law; averaged over the floor area it is

$$
v=-\frac{k_{e f f}}{\mu} \nabla P,
$$

where $k_{\text {eff }}$ is effective air permeability of the floor material $\left[\mathrm{m}^{2}\right]$ and $\mu$ is the viscosity of air $\left[N h / m^{2}\right]$. The pressure gradient throughout the floor can be expressed as $\square P=-\Delta P / d_{f l}$ where $\Delta P$ is the pressure drop and $d_{f l}$ is the floor thickness. Using this expression and 
formula (11) it is easy to obtain the following linear relationship between $\Delta P$ and the averaged air velocity:

$$
\Delta p=G v,
$$

where $G=\mu d_{f l} / k_{\text {eff }}\left[\mathrm{Nh} / \mathrm{m}^{3}\right]$ is the floor resistance to air flow. The inverse parameter, $Y=1 / G\left[\mathrm{~m}^{3} / \mathrm{Nh}\right]$, may be called the flow leakage.

The effective air permeability of the floor material $k_{\text {eff }}$ is a complex and generally unknown function of the porosity of the floor materials and the distributions of cracks, gaps, floor-wall joints and other imperfections. For the generic model considered here it is more practical to estimate floor air resistance $G$ by carrying out experimental measurements on real houses. Unfortunately, such measurements are quite complicated, and there are very few data available in the literature. Those that do exist are not very reliable for the calculations considered here because the air fluxes were measured at comparatively high pressures (50, 75 or $100 \mathrm{~Pa}$ ) and then recalculated to $1 \mathrm{~Pa}$ using the so called flow exponent. It is clear that this procedure is inappropriate for the low pressure differences (1-3 Pa) typical of natural ventilation for which a linear relation between pressure and air velocity is expected. Neverteless, in our worked examples, we have based $G$ values on Dutch recommendations related to floor tightness [9], having corrected them using a linear pressure-velocity relation. For suspended timber floors we use the value $G=27.8 \mathrm{Nh} / \mathrm{m}^{3}$ and for complex layered floors with screed (Fig. 2b) the value $G=139 \mathrm{Nh} / \mathrm{m}^{3}$. 
We remind the reader that, instead of the linear relationship between pressure and flow velocity, many ventilation engineers use the power law for air infiltration through the floor. In our opinion, this is physically incorrect since it contradicts the basic equations of Hydrodynamics for low Reynolds numbers (see, e.g., [10]). For low pressure drops (1 to 3 Pa), which are typical for air flows through gaps and cracks in the floor, the flows are laminar, and air velocity should depend linearly on the applied pressure. The physically justified general expression is the so called "quadratic relationship" [9]. In this relationship, $\Delta P=G v+J v^{2}$, the second term in the right-hand side can be neglected for small flow velocities $v$, and the relationship becomes linear. One should realise, of course, that in practice there might be large holes and gaps in the floor which can introduce noticeable nonlinearity. To define the boundary between linear and nonlinear descriptions for particular floors (i.e., to establish the values of the coefficients $G$ and $J$ ), special experimental investigations are required which would involve measurements of air fluxes through floors at low pressures.

For larger cracks and gaps, and especially for artificial openings (e.g., air bricks and open windows) the behaviour of air flows for typical wind-induced pressures becomes more complex due to turbulence. The averaged air velocities in these cases are essentially larger, and, as follows from the general "quadratic relationship", the relations between averaged air velocities and pressure drops are nonlinear. For example, for a plate containing an orifice the pressure drop over the plate and the averaged air velocity through the orifice are related by the formula

$$
\Delta P=1 / 2 \rho v^{2} / C_{d},
$$


where $C_{d}$ is the so called discharge coefficient which depends on plate thickness. In further calculations we take the value $C_{d}=1$ which is typical for thick plates (walls). One can expect that equation (13) can be applied to openings of arbitrary geometry provided that their dimensions are large enough.

\section{$\underline{\text { Stack effect }}$}

The term stack effect describes an air flux directed upwards and resulting from the pressure difference $\Delta P_{s}$ between the columns of warm and cold air respectively inside and outside a house. This difference may be calculated using the equation of ideal gas and the hydrostatic equation:

$$
\Delta P_{s}=g H_{a v} \rho\left[\left(T_{2}-T_{1}\right) / T_{2}\right],
$$

where $T_{1}$ and $T_{2}$ are absolute temperatures $[K]$ outside and inside the house, $H_{a v}$ is the averaged height of all openings in a living space, and $g$ is the acceleration due to gravity. For example, the averaged temperature difference $\Delta T=T_{2}-T_{1}$ in mild climates may be taken as $9^{0}$ in winter $\left(T_{1}=283 \mathrm{~K}\right.$ and $\left.T_{2}=292 \mathrm{~K}\right)$ and as $0^{0}$ in summer. Hence, the stack effect is important only in winter. The value of $H_{a v}$ varies significantly between individual houses. Therefore, for prudence we use the whole height of a living space $H$ rather than the averaged height of all openings $H_{a v}$. Under such circumstances, for a living space of height $H$ $=5 \mathrm{~m}$ typical values of $\Delta P_{s}$ are around $2 \mathrm{~Pa}$. Assuming air in a living space to be well mixed, and the void temperature equal to the outside temperature, all this pressure difference would be applied to the floor separating the living space from the void. 


\section{$\underline{\text { Air fluxes in a house }}$}

Under equilibrium conditions the total amount of air entering each separate volume (zone) of a house should be equal to the total amount of air leaving the same volume. Introducing the notation $v_{1}^{\text {in }}, v_{1}^{\text {out }}, v_{2}^{\text {in }}, v_{2}^{\text {out }}$ for the averaged velocities of ingoing and outgoing air fluxes in void and living space respectively, and using the notation $v_{12}$ for the averaged velocity of a flux between void and living space, one can write the following balance equations:

$$
v_{1}^{\text {in }} A_{1}^{\text {in }}=v_{1}^{\text {out }} A_{1}^{\text {out }}+v_{12} A_{12}=E_{x 1} V_{1}
$$

for a void, and

$$
v_{2}^{\text {in }} A_{2}^{\text {in }}+v_{12} A_{12}=v_{2}^{\text {out }} A_{2}^{\text {out }}=E_{x 2} V_{2}
$$

for a living space.

Here $A_{1}{ }^{\text {in }}, A_{1}^{\text {out }}, A_{2}^{\text {in }}, A_{2}^{\text {out }}$ are the corresponding total areas of openings in the walls for ingoing and outgoing fluxes, $A_{12}$ is the floor area, $E_{x 1}$ and $E_{x 2}$ are the air exchange rates $\left[h^{-1}\right]$ in void and living space respectively, and $V_{1}, V_{2}$ are the volumes of void and living space.

To facilitate calculation of the pressure distribution and air fluxes throughout a house it is convenient to make use of an analogy between air fluxes and electric currents (Fig. 3). Here the quantities analogous to electromotive forces, which relate to the air bricks on the front and rear walls of a subfloor void, are defined respectively as

$$
\begin{aligned}
& E_{1 f}=P_{1 f}, \\
& E_{1 r}=P_{1 r} .
\end{aligned}
$$


Similarly, forces related to the openings in the front and rear walls of a living space are defined as

$$
\begin{aligned}
& E_{2 f}=P_{2 f}, \\
& E_{2 r}=P_{2 r},
\end{aligned}
$$

where $P_{1 f}, P_{1 r}$ and $P_{2 f}, P_{2 r}$ are the averaged pressures applied to the areas characterised by positive and negative pressure coefficients (front wall and rear and side walls respectively) for a void and for a living space. For stack effect, the equivalent electromotive force is defined as

$$
E_{s}=\Delta P_{s}
$$

The corresponding air flow rates $\left[\mathrm{m}^{3} / \mathrm{h}\right]$, which are analogous to electric currents, are defined as

$$
\begin{aligned}
& I_{1}^{\text {in }}=v_{1}^{\text {in }} A_{1}^{\text {in }}, \\
& I_{1}^{\text {out }}=v_{1}^{\text {out }} A_{1}^{\text {out }}, \\
& I_{2}^{\text {in }}=v_{2}^{\text {in }} A_{2}^{\text {in }}, \\
& I_{2}^{\text {out }}=v_{2}^{\text {out }} A_{2}^{\text {out }},
\end{aligned}
$$

and

$$
I_{12}=v_{12} A_{12}
$$

Relationships between pressure drops across walls and air flow rates (assuming comparatively large openings) are analogous to nonlinear electric resistances:

$$
R_{1}^{i n}\left(I_{1}^{i n}\right)=1 / 2 \rho I_{1}^{i n} /\left(A_{1}^{i n}\right)^{2} 3600,
$$




$$
\begin{aligned}
& R_{1}{ }^{\text {out }}\left(I_{1}{ }^{\text {out }}\right)=1 / 2 \rho I_{1}{ }^{\text {out }} /\left(A_{1}{ }^{\text {out }}\right)^{2} 3600 \text {, } \\
& R_{2}^{i n}\left(I_{2}^{i n}\right)=1 / 2 \rho I_{2}^{i n} /\left(A_{2}{ }^{i n}\right)^{2} 3600, \\
& R_{2}^{\text {out }}\left(I_{2}^{\text {out }}\right)=1 / 2 \rho I_{2}^{\text {out }} /\left(A_{2}^{\text {out }}\right)^{2} 3600 \text {. }
\end{aligned}
$$

They reflect the relationship described above (equation 13) between averaged air velocity and pressure drop through an orifice (the factor 3600 converts air flow rates from $\left[\mathrm{m}^{3} / \mathrm{s}\right]$ to $\left.\left[\mathrm{m}^{3} / \mathrm{h}\right]\right)$. The linear resistance

$$
R_{12}=G / A_{12}=1 / Y A_{12}=\mu d_{f l} / k_{e f f} A_{12}
$$

describes the linear relationship between pressure drop and laminar air flow through a floor.

Calculation of the equivalent problem for electric currents in an electric circuit with linear and nonlinear elements is a complex problem. In this paper we consider a realistic simplification when the air flow rate through the floor $I_{12}$ is much smaller than the input air fluxes through the void and living space $\left(I_{12}<<I_{1}{ }^{i n}\right.$ and $\left.I_{12}<<I_{2}{ }^{i n}\right)$. In this case one can calculate air fluxes through the void and through the living space independently, considering flux through the floor as a small perturbation.

Using the expressions (22) for nonlinear resistances, one can describe the air flow rates $\quad I_{1}$ $=I_{1}^{\text {in }}=I_{1}{ }^{\text {out }}$ and $I_{2}=I_{2}^{\text {in }}=I_{2}^{\text {out }}$ through the void and living space respectively as follows:

$$
I_{1}=\left[\frac{\mathrm{P}_{1 \mathrm{f}}-\mathrm{P}_{1 \mathrm{r}}}{0.5 \rho\left(1 /\left(\mathrm{A}_{1}{ }^{\text {in }}\right)^{2}+1 /\left(\mathrm{A}_{1}{ }^{\text {out }}\right)^{2}\right)}\right]^{1 / 2} 3600,
$$




$$
I_{2}=\left[\frac{\mathrm{P}_{2 \mathrm{f}}-\mathrm{P}_{2 \mathrm{r}}}{0.5 \rho\left(1 /\left(\mathrm{A}_{2}{ }^{\text {in }}\right)^{2}+1 /\left(\mathrm{A}_{2}{ }^{\text {out }}\right)^{2}\right)}\right]^{1 / 2} 3600,
$$

where the factor 3600 converts units from $\left[\mathrm{m}^{3} / \mathrm{s}\right]$ to $\left[\mathrm{m}^{3} / \mathrm{h}\right]$.

The aerodynamic pressures in the void, $P_{1}$, and in the living space, $P_{2}$, which are equivalent to the corresponding electric potentials, $\varphi_{1}$ and $\varphi_{2}$, are determined as

$$
\begin{aligned}
& P_{1}=P_{1 r}+\frac{P_{1 f}-P_{1 r}}{1+\left(A_{1}^{\text {out }}\right)^{2} /\left(A_{1}^{\text {in }}\right)^{2}}, \\
& P_{2}=P_{2 r}+\frac{P_{2 f}-P_{2 r}}{1+\left(A_{2}^{\text {out }}\right)^{2} /\left(A_{2}^{\text {in }}\right)^{2}} .
\end{aligned}
$$

Finally, the air flow rate through the floor, or the floor leakage, $I_{12}\left[\mathrm{~m}^{3} / \mathrm{h}\right]$, may be written as

$$
I_{12}=\left[\Delta P_{s}+\left(P_{1}-P_{2}\right)\right] / R_{12} .
$$

We recall that air exchange rates in void and living space can be written in the form

$$
E_{x 1}=I_{1} / V_{1} \text { and } E_{x 2}=I_{2} / V_{2} \text {. }
$$

Fluxes of a chemical related to the air fluxes

The corresponding ingoing and outgoing fluxes of a contaminant vapour carried by ventilation through the void, living space and through the floor are respectively 


$$
\begin{gathered}
q_{1 v}{ }^{\text {in }} A_{1}{ }^{\text {in }}=I_{1} C_{3}, \\
q_{1 v}{ }^{\text {out }} A_{1}{ }^{\text {out }}=I_{1} C_{1}, \\
q_{2 v}{ }^{\text {in }} A_{2}{ }^{\text {in }}=I_{2} C_{3}, \\
q_{2 v}{ }^{\text {out }} A_{2}^{\text {out }}=I_{2} C_{2},
\end{gathered}
$$

and

$$
q_{12 v} A_{12}=I_{12} C_{1} / S_{a f}
$$

Here $S_{a f}$ is the equivalent air-filled porosity of the floor material, and subscript $v$ means ventilation. In further consideration we assume that the ambient air is unpolluted $\left(C_{3}=0\right)$.

\section{SUCTION FLOW}

In the case of a house with a subfloor void, suction flow (sometimes called pressure-driven flow) occurs because the soil-gas pressure is normally greater than the dynamically modified air pressure inside the void (see previous section). The resulting pressure gradient in the soil $\nabla P$ causes chemical fluxes from soil to subfloor air via connected pore spaces, gaps and cracks. In contrast to thermally induced stack effects, which are important during winter months and negligible in spring and summer, the aerodynamically induced suction flow in a house with a void occurs throughout the year. Note that in houses without voids the aerodynamically generated pressure difference between indoor and outdoor air is also present and contributes to suction flow, although this mechanism is not often mentioned explicitly. Nevertheless, the pressure difference used for calculation of suction flow (e.g., $3.5 \mathrm{~Pa}$ as in Ferguson et al. [2]) is based on empirical data and incorporates the aerodynamic pressure component for typical wind velocities (2-4 m/s). 
The velocity of a suction flow $V_{S}$ driven through a porous medium by a pressure gradient $\nabla P$ is determined from Darcy's law

$$
V_{S}=-\frac{k}{\mu} \nabla P
$$

where $k$ is air permeability in the medium $\left[\mathrm{m}^{2}\right]$ and $\mu$ is the viscosity of air $\left[\mathrm{Nh} / \mathrm{m}^{2}\right]$. The corresponding flux of a chemical driven through the soil by this pressure gradient is

$$
q_{s}=V_{s} C_{0} S_{a},
$$

where $S_{a}$ is the air-filled porosity of soil. The average value of the pressure gradient can be estimated using the simple formula

$$
\nabla P=\left(P_{1}-P_{o d}\right) / d
$$

where $P_{0 d}$ is the dynamic soil-gas pressure which we consider as equal to zero (the total soil-gas pressure $P_{0}$ is, of course, equal to the atmospheric pressure). $P_{1}$ is the dynamic air pressure inside the subfloor void, determined by the expression (26), and $d$ is the characteristic path length of the vapour molecules contributing to the contaminant flux between soil and void [2]. The characteristic path length is determined by the depth of foundations, floor thickness, and location of high-diffusivity channels (gaps and cracks). We use $d=1 \mathrm{~m}$ as an averaged value for typical foundations. According to the previous section, a 
dynamically induced pressure difference between soil and void for a typical wind velocity $v$ $=3 \mathrm{~m} / \mathrm{s}(10.8 \mathrm{~km} / \mathrm{h})$ is $P_{0}-P_{1}=-0.477 \mathrm{~Pa}$.

Effective air permeability through the ground/void boundary is usually dominated by large gaps and cracks located near the foundation perimeter. For simple generic modelling we assume that suction flow through the soil/subfloor system is determined almost entirely by the soil permeability. Considering a reasonable worst case (medium sand soil), we assume in later calculations a soil permeability of $k=10^{-11} \mathrm{~m}^{2}$ [2].

\section{EQUILIBRIUM CONCENTRATIONS OF TOXIC VAPOUR}

At equilibrium the air concentrations of a chemical in each separate volume of a house will be constant. In this case we derive the following balance equations for subfloor void and living space respectively (see Appendix):

$$
\begin{aligned}
& q_{01} A_{g}+q_{s} P L-q_{12} A_{f}-q_{13}\left(A_{w a 1}-A_{h}\right)-q_{1 v}{ }^{\text {out }} A_{1}{ }^{\text {out }}-q_{12 v} A_{f}=0, \\
& q_{12} A_{f}+q_{12 v} A_{f}-q_{23(w)}\left(A_{w a 2}-A_{w d}\right)-q_{23(c)} A_{c}-q_{2 v}{ }^{\text {out }} A_{s 2}{ }^{\text {out }}=0 .
\end{aligned}
$$

Here $A_{g}, \quad A_{f}=A_{12}$ and $A_{C}$ are the surface areas of subfloor ground, floor and ceiling respectively (in further consideration we assume $A_{g}=A_{f}=A_{C}=A$ ), and the indices $(w)$ and (c) attached to $q_{23}$ specify diffusion fluxes through walls and ceiling respectively. Similarly, the relevant areas are denoted by subscripts wa (walls), wd (windows and doors), $c$ (ceiling) and $h$ (holes in the air bricks). Note that in equation (37) windows and doors are considered as impenetrable by contaminants. Any key-holes, gaps at the margins of doors and windows, 
etc. are taken into account through the ventilation flux $q_{2 v}^{\text {out }}$. Similarly, all holes in air bricks are taken into account through the ventilation flux $q_{1 v}{ }^{\text {out }}$.

Before doing further transformations with the coupled system of equations (36) and (37), we need to distinguish between two possible air flow directions through the floor, the reasons for which will be discussed later. We shall consider the air flow rate $I_{12}$ as positive if it is directed from void to living space, and negative for the opposite direction. The contaminant fluxes associated with these air fluxes obviously have different forms, that is $q_{12 v}=I_{12} C_{1}$ for upward flow and $q_{12 v}=I_{12} C_{2}$ for downward flow.

Substituting equations (2) - (8) and (30)-(35) into equations (36) and (37), we can write for the case $I_{12}>0$ :

$$
D_{01}\left(C_{0}-C_{1}\right) A+V_{s} C_{0} P L / S_{a}-D_{12}\left(C_{1}-C_{2}\right) A-D_{13} C_{1}\left(A_{w a 1}-A_{h}\right)-E_{x 1} A H_{1} C_{1}-I_{12} C_{1}=0 \text {, }
$$

$$
D_{12}\left(C_{1}-C_{2}\right) A+I_{12} C_{1}-D_{23(w)} C_{2}\left(A_{w a 2}-A_{w d}\right)-D_{23(c)} C_{2} A-E_{x 2} A H_{2} C_{2}=0 .
$$

Recalling that $C_{0}=C_{V}$ and expressing $C_{V}$ in terms of contaminant concentration in bulk soil $C_{b}$ (see eqn (1)) we solve the system of equations (38), (39) to obtain the following expression for concentration of toxic vapour in the living space: 


$$
\begin{gathered}
C_{2}=\frac{\left(D_{12}+I_{12} / A\right)\left(D_{01}+V_{s} P L / S_{a} A\right) K_{b} C_{b}}{E_{x 1} H_{1}+D_{13}\left(A_{w a 1}-A_{h}\right) / A+D_{01}+D_{12}+I_{12} / A} \bullet \\
{\left[E_{x 2} H_{2}+D_{23(c)}+D_{23(w)}\left(A_{w a 2}-A_{w d}\right) / A+D_{12}-\right.} \\
\left.\frac{D_{12}\left(D_{12}+I_{12} / A\right)}{E_{x 1} H_{1}+D_{13}\left(A_{w a 1}-A_{h}\right) / A+D_{01}+D_{12}+I_{12} / A}\right]^{-1},
\end{gathered}
$$

where $K_{b}$ is determined by formula (1).

Similarly, for the case $I_{12}<0$ we obtain

$$
\begin{gathered}
C_{2}=\frac{D_{12}\left(D_{01}+V_{s} P L / S_{a} A\right) K_{b} C_{b}}{E_{x 1} H_{1}+D_{13}\left(A_{w a 1}-A_{h}\right) / A+D_{01}+D_{12}} \cdot \\
{\left[E_{x 2} H_{2}+D_{23(c)}+D_{23(w)}\left(A_{w a 2}-A_{w d}\right) / A+D_{12}-\right.} \\
\left.I_{12} / A+\frac{D_{12}\left(I_{12} / A-D_{12}\right)}{E_{x 1} H_{1}+D_{13}\left(A_{w a 1}-A_{h}\right) / A+D_{01}+D_{12}}\right]^{-1} .
\end{gathered}
$$

Formulae (40) and (41) describe the equilibrium indoor concentration of a contaminant as a function of contaminant concentration in the bulk soil, wind velocity, and parameters of the house.

In what follows we proceed with the case $I_{12}>0$, i.e., the air flux through the floor is directed from void to living space (formula (40)), which is the most common. The opposite 
case $I_{12}<0$, and its implications for improving air quality in a house, will be discussed later in the worked example.

\section{PERMISSIBLE CONTAMINANT CONCENTRATIONS IN THE BULK SOIL}

In what follows we determine the contaminant concentration in bulk soil that would result in a given running annual average of $C_{2 m}$ (in $\mathrm{ppb}$ ) in the living space when outdoor air is unpolluted $\left(C_{3}=0\right)$ and indoor sources are absent. We first convert from $p p b$ to $\mu \mathrm{g} / \mathrm{cm}^{3}$ by multiplying by the mass density of contaminant vapour (in $\mu \mathrm{g} / \mathrm{cm}^{3}$ ). Assuming for simplicity that summer and winter each last 6 months, the running annual average of the indoor concentration $<C_{2}>$ may be written in the form

$$
<C_{2}>=\left[\left(K_{w}+K_{S}\right) / 2\right] C_{b},
$$

where, according to (40),

$$
\begin{gathered}
K_{w}=\frac{\left(D_{12}+I_{12 w} / A\right)\left(D_{01}+V_{s} P L / S_{a} A\right) K_{b}}{E_{x 1} H_{1}+D_{13}\left(A_{w a 1}-A_{h}\right) / A+D_{01}+D_{12}+I_{12 w} / A} \bullet \\
{\left[E_{x 2} H_{2}+D_{23(c)}+D_{23(w)}\left(A_{w a 2}-A_{w d}\right) / A+D_{12}-\right.} \\
\left.\frac{D_{12}\left(D_{12}+I_{12 w} / A\right)}{E_{x 1} H_{1}+D_{13}\left(A_{w a 1}-A_{h}\right) / A+D_{01}+D_{12}+I_{12 w} / A}\right]^{-1}
\end{gathered}
$$

is a winter-time proportionality coefficient, and 


$$
\begin{gathered}
K_{s}=\frac{\left(D_{12}+I_{12 s} / A\right)\left(D_{01}+V_{s} P L / S_{a} A\right) K_{b}}{E_{x 1} H_{1}+D_{13}\left(A_{w a 1}-A_{h}\right) / A+D_{01}+D_{12}+I_{12 s} / A} \bullet \\
{\left[E_{x 2} H_{2}+D_{23(c)}+D_{23(w)}\left(A_{w a 2}-A_{w d}\right) / A+D_{12}-\right.} \\
\left.\frac{D_{12}\left(D_{12}+I_{12 s} / A\right)}{E_{x 1} H_{1}+D_{13}\left(A_{w a 1}-A_{h}\right) / A+D_{01}+D_{12}+I_{12 s} / A}\right]^{-1}
\end{gathered}
$$

is a summer-time proportionality coefficient. Winter and summer air flow rates, $I_{12 w}$ and $I_{12 s}$, are defined, according to (28), as

$$
I_{12 w}=\left[\Delta P_{s}+\left(P_{1-} P_{2}\right)\right] / R_{12}
$$

and

$$
I_{12 s}=\left(P_{1}-P_{2}\right) / R_{12} .
$$

Replacing $<C_{2}>$ in (42) by $C_{2 m}$ and solving for $C_{b}$ gives

$$
C_{b}=2 C_{2 m} /\left(K_{w}+K_{S}\right) .
$$

This calculation, however, ignores any gradual reduction of contaminant concentration in soil due to volatilisation and other decay processes such as biodegradation. Such processes should be taken into account if the objective is to estimate the initial permissible 
concentration of a contaminant in soil that will not result in exceeding a maximum permissible concentration in indoor air averaged over a lifetime.

We assume that contaminant reduction is a first-order decay process,

$$
d C_{b} / d t=-\alpha C_{b}
$$

which can be solved to give

$$
C_{b}(t)=C_{b}(0) \exp (-\alpha t)
$$

Hence the average concentration in soil over the time interval $\Delta t=t_{\text {max }}-t_{O}$ is given by

$$
<C_{b}>=\frac{\mathrm{C}_{\mathrm{b}}(0)}{\Delta t} \int_{\mathrm{t}_{0}}^{\mathrm{t}_{\max }} \mathrm{e}^{-\alpha \mathrm{t}} \mathrm{dt},
$$

and the initial concentration $C_{b}(0)$ that will give this average is

$$
C_{b}(0)=\frac{\alpha \Delta t<C_{b}>}{e^{-\alpha t_{0}}-e^{-\alpha t_{\max }}}
$$

Without loss of generality, in further calculations we will put $t_{0}=0$. The decay constant $\alpha$ is related to the half-life $t_{1 / 2}$ of a compound in soil by the equation $t_{1 / 2}=\ln (2) / \alpha$. 
Unfortunately, half-lives for organic contaminants in soil are poorly constrained. Literature estimates of degradation half-lives for benzene are as low as 10 days [11]. Half-lives estimated from natural attenuation of benzene in aquifers under aerobic conditions range from 40 to 224 days [12], although under anaerobic conditions benzene appears to resist degradation. For illustration purposes we assume that, for benzene contamination occurring in BTEX mixtures in aerobic unsaturated near-surface soil, a half-life of 1 year is a reasonable choice. This is the same choice made by Jury et al. [4].

\section{EXAMPLE CALCULATIONS: BENZENE VAPOUR IN INDOOR AIR}

In this section we use equations (40), (41), (47) and (51) to calculate a benzene concentration in bulk soil which, averaged over a life-time, will not exceed a prescribed concentration of benzene vapour in indoor air. Two structural forms of housing are considered (Figs. 2a and 2b), and, for illustration purposes, the prescribed indoor air concentration is taken as $5 \mathrm{ppb}$ running annual average [13]. Data used in the calculations are summarised in Table 1.

\section{Example 1: Suspended timber floor with oversite concrete}

In the case of a void between a suspended timber floor and a foundation with oversite concrete (Fig. 2a), the effective molecular diffusivities are calculated from equation (4) with the molecular diffusivity of benzene in air taken as $D_{a}=1.8 \times 10^{-2} \mathrm{~m}^{2} / \mathrm{h}$ [3]. Then, using the layer thickness values in Table 1, diffusion coefficients for the ground/void boundary are calculated as follows: 
hardcore:

blinding sand:

oversite concrete:

$$
\begin{aligned}
& D_{h c}=7.0 \times 10^{-3} \mathrm{~m} / \mathrm{h}, \\
& D_{S}=1.43 \times 10^{-1} \mathrm{~m} / \mathrm{h}, \\
& D_{C}=4.96 \times 10^{-4} \mathrm{~m} / \mathrm{h} .
\end{aligned}
$$

Substituting these values into equation (3) gives the following value for the coefficient of molecular diffusion $D_{01}$ between the soil and subfloor void compartments:

$$
D_{01}=4.62 \times 10^{-4} \mathrm{~m} / \mathrm{h} \text {. }
$$

Calculation of the diffusion coefficient $D_{12}$ for a suspended timber floor using formula (5) gives the following value:

$$
D_{12}=5.7 \times 10^{-2} \mathrm{~m} / \mathrm{h} \text {. }
$$

Similarly, the coefficients of molecular diffusion between the living space and outdoor air compartments, $D_{23}$, through walls $(w)$ and ceiling $(c)$ are:

$$
\begin{array}{ll}
D_{23}(w) & =3 \times 10^{-3} \mathrm{~m} / \mathrm{h}, \\
D_{23}(c) & =3.5 \times 10^{-2} \mathrm{~m} / \mathrm{h} .
\end{array}
$$

The suction flow velocity $V_{s}$ from soil to void driven by dynamically induced negative pressure in a void is calculated using equations (26) and (33)-(35) for a given wind speed and subfloor void parameters. The average path length of the flux beneath outside walls is taken as $d=1 \mathrm{~m}$, and air viscosity as $\mu=5 \times 10^{-9} \mathrm{Nh} / \mathrm{m}^{2}$. The characteristic width of ground outside the house walls over which suction flow is effective is taken as $L=0.5 \mathrm{~m}$. As a 
conservative choice for the value of soil permeability, we use $k=10^{-11} \mathrm{~m}^{2}$ representing medium sands.

As an idealisation we assume that all openings are distributed equally over the four exterior walls, and we take the following typical areas of input and output openings: $A_{1}{ }^{i n}=0.01 \mathrm{~m}^{2}$, $A_{1}{ }^{\text {out }}=0.03 \mathrm{~m}^{2}$ for a subfloor void, and $A_{2}{ }^{\text {in }}=0.02 \mathrm{~m}^{2},{A_{2}}^{\text {out }}=0.06 \mathrm{~m}^{2}$ for a living space. Note that values for a void (total area of holes in airbricks) correspond to the recommended value of $1500 \mathrm{~mm}^{2}$ per $1 \mathrm{~m}$ of wall [9]. For a typical wind velocity of $v=3 \mathrm{~m} / \mathrm{s}$ at the reference height of $10 \mathrm{~m}$, and for the values of pressure coefficients discussed in Section 4, we obtain the dynamic pressures for a void, $P_{1 f}=0.188 \mathrm{~Pa}, P_{1 r}=-0.657 \mathrm{~Pa}$, and for a living space, $P_{2 f}=3.76 \mathrm{~Pa}, P_{2 r}=-3.28 \mathrm{~Pa}$. The resulting air flow rates through void and living space are $I_{1}=39.0 \mathrm{~m}^{3} / \mathrm{h}$ and $I_{2}=226 \mathrm{~m}^{3} / \mathrm{h}$ respectively. These correspond to air exchange rates of $E_{x 1}=3.26 h^{-1}$ and $E_{x 2}=0.752 h^{-1}$. The dynamic pressures inside the void and living space are $P_{1}=-0.572 \mathrm{~Pa}$ and $P_{2}=-2.58 \mathrm{~Pa}$. The value of the stack induced pressure difference between void and living space in winter is $1.95 \mathrm{~Pa}$. Thus the air flux through the floor, $I_{12}$, in the case under consideration is directed from a void to a living space and for $G=27.8 \mathrm{Nh} / \mathrm{m}^{3}$ takes the value $I_{12 \mathrm{w}}=8.50 \mathrm{~m}^{3} / \mathrm{h}$ in winter and $I_{12 \mathrm{~s}}=4.34$ $\mathrm{m}^{3} / \mathrm{h}$ in summer. The suction flow velocity $V_{s}$ through soil to void is equal to $1.0 \times 10^{-3} \mathrm{~m} / \mathrm{h}$ for a wind velocity of $3 \mathrm{~m} / \mathrm{s}$ at $10 \mathrm{~m}$ height. The above results are consistent with the corresponding values calculated using the BREVENT finite-difference model [6].

We now calculate the initial benzene concentration in bulk soil that would give a running annual average of $C_{2}=5 \mathrm{ppb}$ benzene in the living space when outdoor air is unpolluted and indoor sources are absent. Calculation carried out according to (43)-(47) and (51) gives the following value of the initial concentration: 


$$
C_{b}(0)=51.5 \mathrm{mg} / \mathrm{kg}
$$

This result can be considered as providing an upper bound estimate because the calculation neglects exposure pathways other than inhalation of indoor air.

Dependence of the initial permissible concentration $C_{b}(0)$ on wind velocity $v$ (Figure 4) shows that for the house parameters under consideration all curves, which refer to different half-lives of benzene in soil, have a maximum around $v=2 \mathrm{~m} / \mathrm{s}$. The reason for these maxima is clear. For small wind speeds, the combined effect of ventilation in both void and living space increases the initial permissible concentration. For greater wind speeds, the decrease in concentration reflects the increase in air infiltration from void to living space, $I_{12}$ , and suction flow from soil to void, $V_{s} P L$. The air flow rates $I_{1}, I_{2}$ and $I_{12}$ as functions of wind velocity $v$ are shown on Fig. 5. Figure 6 illustrates the resulting linear relationships between wind velocity $v$ and the air exchange rates $E_{x 1}$ (void) and $E_{x 2}$ (living space). If we now consider a floor made completely impenetrable to dynamic air flow (formally this may be taken into account by making use of the limiting case $G \rightarrow \infty$ ), then a significant increase in $C_{b}(0)$ occurs (Fig. 7). This demonstrates the effectiveness of air tight floors, as expected.

The above example dealt with the situation when all openings in a house are evenly distributed between the exterior walls. Let us now consider a situation where such symmetry is broken, say by opening a small window on the windward face (front) of a living space. Taking the area of openings in the front wall as $A_{2}^{i n}=0.12 \mathrm{~m}^{2}$ (instead of $A_{2}^{i n}=0.02 \mathrm{~m}^{2}$ used above), with other parameters unchanged, results in a dynamic pressure in the void of $P_{1}=-0.572 \mathrm{~Pa}$ and in the living space of $P_{2}=2.35 \mathrm{~Pa}$ for a wind speed of $v=3 \mathrm{~m} / \mathrm{s}$. This 
produces negative signs for the air flow through the floor both in winter and summer $\left(I_{12 w}\right.$ $\left.=-2.14 \mathrm{~m}^{3} / \mathrm{h}, I_{12 \mathrm{~s}}=-6.31 \mathrm{~m}^{3} / \mathrm{h}\right)$, i.e., the direction of air flow is from living space to void. The calculated air flow rates are shown in Fig. 8, the corresponding air exchange rates in Fig. 9, and the initial concentrations of benzene in bulk soil resulting in the recommended Air Quality Standard are shown in Fig. 10. As expected, changing the direction of air flow $I_{12}$ results in a large increase in the initial contaminant concentration in bulk soil, the behaviour being similar to that associated with a completely air-tight floor (Fig. 7). Thus, simply keeping a window open in the windward wall is a remarkably effective way of minimising ingress of toxic vapours into a house. Note that opening a window in the leeward wall (which is perhaps more likely on windy days) results in an increase of contaminant concentration in indoor air.

\section{Example 2: Suspended beam and block floor without oversite concrete}

All calculations for this type of construction (Fig. 2b) are similar to those for the previous one. Using layer thickness values from Table 1, the diffusion coefficients for the ground/void boundary are calculated as

$$
\begin{array}{ll}
\text { hardcore: } & D_{h c}=7.0 \times 10^{-3} \mathrm{~m} / \mathrm{h}, \\
\text { blinding sand: } & D_{S}=1.43 \times 10^{-1} \mathrm{~m} / \mathrm{h} .
\end{array}
$$

Substituting these values into equation (3) yields a value for the coefficient of molecular diffusion between soil and subfloor void of $D_{01}=7.0 \times 10^{-3} \mathrm{~m} / \mathrm{h}$.

Calculation of the diffusion coefficient $D_{12}$ for the suspended floor with screed gives 


$$
D_{12}=2.3 \times 10^{-2} \mathrm{~m} / \mathrm{h} \text {. }
$$

The coefficients of molecular diffusion between living space and outdoor air compartments, $D_{23}$, through walls $(w)$ and ceiling $(c)$ remain unchanged:

$$
\begin{aligned}
& D_{23}(w)=\quad 3 \times 10^{-3} \mathrm{~m} / \mathrm{h} \\
& D_{23}(c)=3.5 \times 10^{-2} \mathrm{~m} / \mathrm{h} .
\end{aligned}
$$

For typical areas of input and output openings in void and living space $\left(A_{1}{ }^{i n}=0.01 \mathrm{~m}^{2}\right.$, $A_{1}{ }^{\text {out }}=0.03 \mathrm{~m}^{2}$, and $A_{2}{ }^{\text {in }}=0.02 \mathrm{~m}^{2}$ and $A_{2}{ }^{\text {out }}=0.06 \mathrm{~m}^{2}$ ) and for wind velocity $v=3 \mathrm{~m} / \mathrm{s}$, we obtain the same values of air exchange rates in a void and in a living space, $E_{x 1}=3.26 h^{-1}$ and $E_{x 2}=0.752 \mathrm{~h}^{-1}$, as in the suspended timber floor construction. The stack induced pressure difference between void and living space in winter also remains unchanged at 1.93 $P a$. However, the greater degree of air-tightness of a beam and block floor with screed $(G=$ $\left.139 \mathrm{Nh} / \mathrm{m}^{3}\right)$ relative to a suspended timber floor $\left(G=27.8 \mathrm{Nh} / \mathrm{m}^{3}\right)$, results in lower values of air flux through the floor, $I_{12 w}=1.70 \mathrm{~m}^{3} / \mathrm{h}$ in winter and $I_{12 \mathrm{~s}}=0.867 \mathrm{~m}^{3} / \mathrm{h}$ in summer.

The resulting initial benzene concentration in bulk soil that would give a running annual average of $C_{2}=5 \mathrm{ppb}$ benzene in the living space air is

$$
C_{b}(0)=38.1 \mathrm{mg} / \mathrm{kg} \text {. }
$$

This is lower than for the suspended timber floor under the same conditions because the absence of oversite concrete results in a higher diffusive flux into the void. This gives rise to 
a greater benzene concentration in living space air, despite a lower ventilation flux through the floor.

Dependence of the initial permissible concentration of benzene in soil, $C_{b}(0)$ on wind velocity for this construction (Fig. 11) shows that the maxima (corresponding to different half-lives of benzene in soil) are displaced to higher wind velocities, around $v=5 \mathrm{~m} / \mathrm{s}$. This reflects the reduced air infiltration from void to living space through a tighter floor.

\section{Example 3: Suspended timber floor without oversite concrete}

This construction, which is common in the existing U.K. housing stock, is a variant of the suspended timber floor considered at the beginning of this section (Fig. 2a).

For parameter values the same as before, the initial benzene concentration in bulk soil that would give a running annual average of $C_{2}=5 \mathrm{ppb}$ benzene in living space air is

$$
C_{b}(0)=8.16 \mathrm{mg} / \mathrm{kg}
$$

This is substantially lower than for the previously considered constructions, reflecting both an increased diffusion flux into the void and relatively large air flux from void to living space through a relatively leaky timber floor.

Dependence of the initial permissible concentration $C_{b}(0)$ for this construction on wind velocity $v$ is shown for an equal distribution of openings between the walls, $A_{1}{ }^{i n}=0.01 \mathrm{~m}^{2}$, $A_{1}{ }^{\text {out }}=0.03 \mathrm{~m}^{2}$, and $A_{2}{ }^{\text {in }}=0.02 \mathrm{~m}^{2},{A_{2}}^{\text {out }}=0.06 \mathrm{~m}^{2}$ (Fig. 12) and for the case of an 
additional window open on the windward wall, $A_{1}{ }^{\text {in }}=0.01 \mathrm{~m}^{2}, A_{1}{ }^{\text {uut }}=0.03 \mathrm{~m}^{2}$, and $A_{2}{ }^{\text {in }}=$ $0.12 \mathrm{~m}^{2}, \mathrm{~A}_{2}{ }^{\text {out }}=0.06 \mathrm{~m}^{2}$ (Fig. 13). As before, opening a window on the windward wall results in a large increase in the permissible initial concentration of benzene in soil.

Example 4: Suspended timber floor without oversite concrete in the absence of subfloor $\underline{\text { ventilation }}$

This type of void differs from the previous one only by the absence of subfloor void openings (airbricks); that is, $A_{1}^{\text {in }}$ and $A_{1}^{\text {out }}$ are both set equal to zero. This analysis needs some caution because the limits $A_{1}{ }^{\text {in }} \rightarrow 0$ and $A_{1}{ }^{\text {out }} \rightarrow 0$ in the formulae for calculating aerodynamic pressures and air fluxes inside a house are invalid in the perturbation approach used in this paper. We recall that the perturbation approach requires input air fluxes in both void and living space to be much larger than the air flux between void and living space: $I_{1}^{\text {in }}>>I_{12}$ and $I_{2}{ }^{\text {in }}>>I_{12}$. To avoid this difficulty, one needs additional assumptions, which are quite reasonable; namely, that the steady-state air pressure in an unventilated subfloor void is equal to the pressure in a living space $\left(P_{1}=P_{2}\right)$ and that the air temperatures in void and living space are is equal. It follows from these assumptions that there is no air flux between void and living space $\left(I_{12}=0\right)$ and both the stack pressure difference and the aerodynamically induced pressure in a living space are applied to the foundation. The resulting pressure difference $\Delta P_{f}=\Delta P_{s}+P_{1}$, where $\Delta P_{s}$ is a stack pressure, drives a suction flow inside the house. For wind velocity $v=3 \mathrm{~m} / \mathrm{s}$ and other house parameters as before, we have $\Delta P_{s}=$ 1.93 $\mathrm{Pa}$ and $P_{1}=-2.58 \mathrm{~Pa}$ that result in $\Delta P_{g b}=4.51 \mathrm{~Pa}$. This value of $\Delta P_{f}$ is close to the empirically determined default value of $3.5 \mathrm{~Pa}$ used in earlier work to calculate a suction 
flow [2]. Note, however, that for higher wind velocities, the aerodynamically induced pressure $P_{1}$ increases and this should be taken into account.

Thus, setting $P_{1}=P_{2}$ substituting expressions for the velocity of a suction flow in winter, $V_{s w}=\left(\Delta P_{s}+P_{1}\right)(k / \mu d)$, and summer, $V_{s s}=P_{1}(k / \mu d)$, into (40), (42) and (47), we calculate the initial benzene concentration in bulk soil that would give a running annual average of $C_{2}$ $=5 \mathrm{ppb}$ in living space air:

$$
C_{b}(0)=1.37 \mathrm{mg} / \mathrm{kg} \text {. }
$$

Dependence of $C_{b}(0)$ on wind velocity is shown in Fig. 14. The model predicts values of permissible initial bulk-soil concentration which are by far the most stringent for all constructions considered. This illustrates the importance of subfloor void ventilation for limiting the ingress of soil vapours into the living spaces of houses.

\section{Example 5: House based on concrete raft foundation}

This type of construction style is treated in the model as a variant of the construction with a suspended timber floor in the absence of subfloor ventilation. The difference is in the presence of a monolithic concrete raft foundation which, assuming that there are no cracks, entirely protects the house against suction flow. The no-crack assumption is rather stringent and may be considered realistic only for newly built houses. In time, the effects of moisture, temperature change, ground subsidence, etc. will inevitably cause concrete degradation and result in the appearance of micro- and macrocracks making the concrete layer more penetrable for air flow. Unfortunately, there are no reliable data on degradation of concrete 
raft foundations used in house construction and the time taken to significantly increase air permeability. In this paper it is taken to be larger then 5 years. Since the half-life of benzene in soil is assumed to be 1 year, we ignore time-degradation of concrete in the context of modelling benzene ingress. For other contaminants, or for ground gases with continuous sources, lack of information on concrete raft degradation may prove a more serious obstacle to modelling.

Taking the typical thickness of a concrete raft as $0.3 \mathrm{~m}$, with other house parameters and wind velocity unchanged, we obtain the following initial benzene concentration in bulk soil that would give a running annual average of $C_{2}=5 \mathrm{ppb}$ in living space air:

$$
C_{b}(0)=123 \mathrm{mg} / \mathrm{kg} \text {. }
$$

Concentration $C_{b}(0)$ as a function of wind velocity is shown in Fig. 15. In contrast to the previous construction styles, the values of $C_{b}(0)$ depend linearly on wind velocity. This is because, in the absence of suction flow, the ingoing diffusive flux of benzene does not depend on wind velocity.

\section{Example 6: Semidetached and terraced houses}

From the point of view of dynamically-induced pressure applied to the external walls, the detached, semi-detached and terraced houses differ from each other only by the house length to width ratio $s$. For detached houses we assumed that $s=1$. Then, for semi-detached houses $s=2$, and for terraced houses $s \geq 2$. Unfortunately, there is a lack of data in the literature regarding pressure coefficients for houses with different length to width ratios. For 
example, in Orme et al [9] only data for the ratio values of 1 and 2 are present (see pages 8287). Note, however, that averaged values of the pressure coefficients for these two cases do not differ much from each other. Taking this into account and supposing that the same situation takes place for terraced houses (at least for values of $s$ not much larger than 2), we assume that pressure coefficients used for detached houses may be equally applied for external walls of semi-detached and terraced houses. We realise that this is probably not true for long terraced houses. However, we repeat that there are no data for this case at all.

To illustrate the effects in principle, we consider semidetached and terraced houses having suspended timber floors with oversite concrete. We take the living space volumes for both as $V_{2}=187.5 \mathrm{~m}^{3}$, and the perimeter of exterior walls as $P=17.5 \mathrm{~m}$ for a semidetached house and $P=10 \mathrm{~m}$ for a terraced house.

Since semidetached and terraced houses have respectively three and two exterior walls, the dominant wind direction in the given locality should ideally be taken into account. For simplicity, however, we assume that the wind direction pattern is isotropic (equally distributed over the range $0-360^{\circ}$ ) over a relatively long period of time.

Assuming that the total area of openings in each exterior wall is $0.01 \mathrm{~m}^{2}$ (void) and $0.02 \mathrm{~m}^{2}$ (living space) in both types of house, we consider the relations between total areas of wall openings for ingoing and outgoing air fluxes corresponding to four wind directions (perpendicular to each wall). Since void and living space do not differ in this sense we give the results for voids, assuming that the wind direction $0^{0}$ corresponds to wind directed towards the internal wall. The total area of openings for ingoing and outgoing fluxes corresponding to different wind directions are, for semidetached houses: 


\begin{tabular}{llllll}
\hline Wind direction & $0^{0}$ & $90^{0}$ & $180^{0}$ & $270^{0}$ & Averaged \\
\hline $\mathrm{A}_{1}{ }^{\text {in }}$ & 0 & $0.01 \mathrm{~m}^{2}$ & $0.01 \mathrm{~m}^{2}$ & $0.01 \mathrm{~m}^{2}$ & $0.075 \mathrm{~m}^{2}$ \\
$\mathrm{~A}_{1}{ }^{\text {out }}$ & $0.03 \mathrm{~m}^{2}$ & $0.02 \mathrm{~m}^{2}$ & $0.02 \mathrm{~m}^{2}$ & $0.02 \mathrm{~m}^{2}$ & $0.0225 \mathrm{~m}^{2}$ \\
\hline
\end{tabular}

and for terraced houses:

\begin{tabular}{llllll}
\hline Wind direction & $0^{0}$ & $90^{0}$ & $180^{0}$ & $270^{0}$ & Averaged \\
& & & & & \\
\hline $\mathrm{A}_{1}{ }^{\text {in }}$ & 0 & $0.01 \mathrm{~m}^{2}$ & 0 & $0.01 \mathrm{~m}^{2}$ & $0.05 \mathrm{~m}^{2}$ \\
$\mathrm{~A}_{1}{ }^{\text {out }}$ & $0.02 \mathrm{~m}^{2}$ & $0.01 \mathrm{~m}^{2}$ & $0.02 \mathrm{~m}^{2}$ & $0.01 \mathrm{~m}^{2}$ & $0.015 \mathrm{~m}^{2}$ \\
& & & & & \\
\hline
\end{tabular}

Note that despite different relations between $A_{1}^{\text {in }}$ and $A_{1}{ }^{\text {out }}$ for different wind directions, and the different averaged values, the ratio between averaged values of $A_{1}{ }^{\text {in }}$ and $A_{1}{ }^{\text {out }}$ is equal to $1 / 3$ for both semidetached and terraced houses, and that this ratio is the same for detached houses. Thus, for an isotropic wind pattern, semidetached and terraced houses differ from detached houses only by the absolute values of $A_{1}^{\text {in }}$ and $A_{1}{ }^{\text {out }}$. The same conclusions apply also to openings in living spaces.

Taking the above idealisation into account, with other parameters unchanged, we obtain the following initial permissible benzene concentration in bulk soil: 


$$
C_{b}(0)=77.0 \mathrm{mg} / \mathrm{kg}
$$

for semidetached houses, and

$$
C_{b}(0)=55.1 \mathrm{mg} / \mathrm{kg}
$$

for terraced houses.

Variation in the initial concentration $C_{b}(0)$ as a function of wind velocity for both semidetached and terraced houses is similar to that for the corresponding detached house. Although this idealised example considers an equal distribution of wind directions, other distributions can be modelled by weighted averaging of the total areas of ingoing and outgoing air fluxes over all possible wind directions.

\section{Example 7: Effects of cover systems}

The effects of replacing an upper layer of contaminated soil on a site by clean fill depend strongly on the cover layer thickness. If the cover thickness is less than the foundation depth (about $0.5 \mathrm{~m}$ for the case considered), then the clean fill reduces the diffusive flux of contaminant from soil, but does not significantly influence the suction flow. Calculations for a house with oversite concrete and suspended timber floor, built on a site with a $0.5 \mathrm{~m}$ clean cover layer, show that for wind velocity $3 \mathrm{~m} / \mathrm{s}$ the initial permissible concentration of benzene in soil is

$$
C_{b}(0)=54.7 \mathrm{mg} / \mathrm{kg}
$$


This is hardly different from the case where no soil replacement takes place $\left(C_{b}(0)=51.5\right.$ $\mathrm{mg} / \mathrm{kg}$ ). However, if the cover layer thickness increases to greater than $0.5 \mathrm{~m}$, the clean fill starts to reduce contaminant flux via suction flow. The reduction occurs because a significant part of the suction flow runs through clean fill, resulting in a reduction in contaminant flux despite the suction air flow rate being unchanged. Detailed calculation of $C_{b}(0)$ as a function of layer depth is quite complex and needs special consideration. However, for comparatively thick cover layers $(>1 \mathrm{~m}$ ), it is possible to conclude that almost all suction flow will be concentrated inside clean fill. This implies that contaminant flux in this case is no longer associated with suction flow. Calculation for a cover layer thickness of $1 \mathrm{~m}$ implies that elimination of benzene ingress via suction flow combined with reduced diffusive flux results in a large increase in the initial permissible concentration:

$$
C_{b}(0)=357 \mathrm{mg} / \mathrm{kg} \text {. }
$$

Dependence of $C_{b}(0)$ on wind velocity is shown in Fig. 16. Absence of maxima, due to the absence of a suction flow, implies that for higher wind velocities the values of $C_{b}(0)$ are even larger.

\section{Example 8: Docklands type of housing development}

“Docklands Type” development refers to houses built with external hardstanding. The influence of hardstanding on the initial permissible concentration in soil is mainly associated with possible changes in contaminant suction flow. In the very idealised situation when there are no cracks or gaps in the hardstanding, one would expect suction flow to be entirely 
eliminated. Calculation for a house having a suspended timber floor with oversite concrete shows that if this is the case, the initial permissible concentration of benzene in soil is

$$
C_{b}(0)=216 \mathrm{mg} / \mathrm{kg}
$$

In real situations, however, construction practices combined with relative movements of house and hardstanding will often result in relatively large cracks and gaps in the junctions between walls and hardstanding. This situation is then not much different from houses without external hardstanding. Even if cracks and gaps at junctions are regularly sealed, the influence of use and weathering on unprotected hardstanding will result in numerous microcracks. These microcracks will have two related effects on the suction flow contribution: a) increase in average path length for suction flow $d$, and b) increase in characteristic flow width $L$. Since the parameters $d$ and $L$ contribute to suction flow in opposite ways (formulae (33)-(35) and (40)), their effects nearly cancel each other. Thus, for this type of development a realistic value of permissible initial benzene concentration in soil is the same as for houses built without external hardstanding, i.e. $C_{b}(0) \approx 50 \mathrm{mg} / \mathrm{kg}$.

\section{CONCLUSIONS}

The results derived from the model indicate that penetration of toxic soil vapours into living spaces of houses with subfloor voids is strongly influenced by void construction and by wind velocity. Worked examples are used to illustrate the ability of different construction styles to resist the ingress of benzene vapour into living space air. 
The example calculations suggest:

(I) When all openings in a house are equally distributed between the four external walls, the initial benzene concentration in bulk soil that would give a running annual average of $5 \mathrm{ppb}$ in living space air depends on wind velocity, with maxima around 2-6 m/s (Figs. 4, 11, and 12). These maxima reflect the increase of air infiltration from void to living space via ventilation flux through a floor and aerodynamically driven suction flow from soil to a void, with increasing wind velocity.

(ii) If the area of openings on the windward wall of a living space is significantly larger than that for other walls, then the ventilation flux through the floor reverses and is directed from living space to void. This cuts off the ventilation mechanism of vapour transport from void to living space and results in a large increase in the maximum permissible initial concentration in bulk soil (Figs. 10 and 13). In this case, the initial concentration of contaminant in soil as a function of wind velocity has no maximum and is similar to the dependence for an ideally airtight floor (Fig. 7). This effect might be considered for improving indoor air quality by opening a special ventilation window on a windward wall, perhaps making use of a specially designed automatic control system.

(iii) Comparison of different construction styles from the point of view of their simulated efficiency in reducing indoor air contamination implies that the best construction is one involving a suspended timber floor and oversite concrete. Taking into account that averaged wind speed in the UK is around $3 \mathrm{~m} / \mathrm{s}$ and the illustrative value of maximum permissible contaminant concentration in indoor air is $5 \mathrm{ppb}$, a maximum tolerable concentration of benzene in soil of about $50 \mathrm{mg} / \mathrm{kg}$ is indicated. 
(iv) A house with suspended beam and block floor with screed, but without oversite concrete, is probably of comparable resistance to vapour ingress since the absence of oversite concrete is partly compensated by the more air-tight suspended floor. Although the initial bulk-soil concentration calculated in the worked example for this case shows a lower value, $C_{b}(0)=38.1 \mathrm{mg} / \mathrm{kg}$, it is natural to consider both construction styles as equally resistant to indoor air contamination.

A house with suspended timber floor, but without oversite concrete (which is common in the existing U.K. housing stock), is expected to be less resistant to vapour ingress; the initial bulk-soil concentration calculated in the worked example is $C_{b}(0)=8.16 \mathrm{mg} / \mathrm{kg}$.

(v) A house with unventilated void comprising a suspended timber floor and having no oversite concrete is the worst from the point of view of its resistance to vapour ingress $\left(C_{b}(0)=1.37 \mathrm{mg} / \mathrm{kg}\right.$ in the worked example). This illustrates the importance of subfloor ventilation for indoor air quality in houses built on soils where vapour intrusion may be a problem.

(vi) A concrete raft foundation provides relatively high protection against ingress of soil vapours. However, the model estimate of the initial permissible concentration of benzene in soil, $C_{b}(0)=123 \mathrm{mg} / \mathrm{kg}$, assumes that concrete degrades very slowly relative to the half-life of the contaminant in soil.

(vii) Calculated values of the maximum initial concentration of benzene in soil for semidetached and terraced houses with suspended timber floors are close to the value for a corresponding detached house at $C_{b}(0)=50-80 \mathrm{mg} / \mathrm{kg}$. 
(viii) The model indicates that Cover systems can have a significant effect on soil vapour ingress if the thickness of the replaced soil layer is larger than the depth of foundation. In this case suction flow is confined to the clean cover layer. Combined with the decrease in diffusive flux, this dramatically reduces simulated vapour ingress and leads to a large increase in calculated permissible concentration of benzene in soil. For houses with suspended timber floor and oversite concrete the calculated value is $C_{b}(0)=357 \mathrm{mg} / \mathrm{kg}$ compared with $C_{b}(0)$ $=51.5 \mathrm{mg} / \mathrm{kg}$ for the same house without cover system.

(ix) From the simulations, Docklands type developments would appear to provide excellent protection against intrusion of soil vapours if there were no cracks or gaps at the junctions between walls and hardstanding, or in the hardstanding. In such an ideal situation suction flow would be eliminated resulting in a large permissible initial concentration of benzene in soil. Realistically, however, we expect such gaps and cracks to exist. Docklands type developments are therefore likely to behave in essentially the same way as developments without external hardstanding.

\section{ACKNOWLEDGEMENTS}

This work forms part of a research project funded by the UK Department of the Environment, Transport and the Regions. However, the opinions expressed in this paper and the results of the numerical calculations presented for illustration only are those of the authors alone and should not be taken to represent those of the Department. We are grateful to Richard Hartless and Andrew Cripps (Air Quality Division of the Building Research Establishment) for 
useful discussions on ventilation problems, and for providing a copy of the BREVENT software; and to Douglas Laidler (Parkman Environment) for helpful comments on the paper.

\section{REFERENCES}

1. C.C. Ferguson, The Contaminant Land Exposure Assessment Model (CLEA): Technical Basis and Algorithms, Report prepared for Department of the Environment under Contracts PECD 7/10/305 and PECD 7/10/337.

2. C.C. Ferguson, V.V. Krylov and P.T. McGrath, Contamination of indoor air by toxic vapours: a screening risk assessment model, Building and Environment, 30, 375-383 (1995).

3. W.W. Nazaroff, WW H. Feustel, A. V. Nero, K. L. Rezvan, D. T. Grimsrud, M. A. Essling and R. E. Toohey, Radon transport into a detached one-story house with a basement, Atmosph. Env., 19, 31-46 (1985).

4. W.A. Jury, D. Russo, G. Streile and E. A. Hesham, Evaluation of votalization by organic chemicals residing below the soil surface, Water Resource Research, 26, 13 - 20 (1990).

5. L.J. Thibodeaux and H. D. Scott, Air/soil exchange coefficients, In: Environmental Exposure from Chemicals, W.B. Neely and G.E. Blau, eds. Vol.1, CRC Press, Boca Raton (USA), (1985). 
6. BREVENT: Software package to predict ventilation rates in dwellings, Building Research Establishment, Garston, U.K. (1992).

7. British Standards Institution (BSI), Code of practice for ventilation principles and designing for natural ventilation, British Standard BS5925: 1991, London, BSI (1991).

8. V.V. Baturin, Fundamentals of industrial ventilation, Pergamon Press, Oxford (1972).

9. M. Orme, M. Liddament and A. Wilson, An analysis and data summary of the AIVC's numerical database: Technical Note AIVC 44, Air Infiltration and Ventilation Centre, University of Warwick, March (1994).

10. G.K. Batchelor, An Introduction to Fluid Dynamics, Cambridge University Press, Cambridge (1994).

11. P. Howard et al., Handbook of Environmental Degradation Rates, Lewis Publishers Inc., Chelsea, MI (1991).

12. Natural Attenuation. Issue 2 of BP Green (Groundwater Remediation and Environmental Engineering News), BP Oil Environmental Technology, Cleveland, Ohio (1994).

13. DOE [Department of the Environment] Expert Panel on Air Quality Standards: Benzene, H.M.S.O., London (1994). 


\section{APPENDIX \\ DERIVATION OF THE CONCENTRATION BALANCE EQUATIONS}

In the presence of indoor sources of a polluting gas in a macroscopic point considered, the differential equation describing the time and space evolution of gas concentration may be written in the form

$$
\partial C / \partial=\left(\nabla \cdot D_{e f f} \nabla C\right)-(\nabla \cdot C v) / S_{a}+J
$$

Here $C$ is concentration of a chemical in air, $D_{\text {eff }}$ is effective molecular diffusivity, $\boldsymbol{v}$ is the velocity vector of a hydrodynamic flow, $S_{a}$ is the air-filled porosity (where appropriate), and $J$ is the density of indoor sources of a polluting gas. Note that in the absence of hydrodynamic flows $(v=0)$ or gradient of concentration $(\nabla C=0)$ equation (A1) reduces respectively either to the equation of diffusion or to the hydrodynamic continuity equation for porous media written in terms of concentration.

Integrating eqn (A1) over the volume of interest $V$ bounded by the closed surface $S$ (which may be chosen inside the outer material boundaries of each separate volume of the house) and using the divergence theorem, one can get for each volume (zone)

$$
(\partial / \partial) \int_{\mathrm{V}} \mathrm{CdV}=\oint_{\mathrm{S}} \mathrm{D}_{\mathrm{eff}}(\boldsymbol{n} \cdot \nabla C) \mathrm{d} S-\oint_{\mathrm{S}} \mathrm{C}(\boldsymbol{v} \cdot \boldsymbol{n}) \mathrm{dS}+\int_{\mathrm{V}} \mathrm{JdV},
$$


where $\boldsymbol{n}$ is a unit vector normal to the surface and directed outside the closed volume. For steady-state or very slowly-varying processes, the term with time derivative in (A2) can be neglected, and it follows that

$$
\oint_{S} \mathrm{D}_{\mathrm{eff}}(\boldsymbol{n} \cdot \nabla C) d S-\oint_{\mathrm{S}} \mathrm{C}(\boldsymbol{v} \cdot \boldsymbol{n}) d S+I=0
$$

where we have introduced the notation $I=\int_{\mathrm{V}} \mathrm{JdV}$ for the total productivity of indoor sources of a polluting gas. Note that quantities $D_{\text {eff }}, \nabla C$ and $\boldsymbol{v}$ in eqn (A3) are generally functions of the position on the surface.

In further transformations we use standard definitions of diffusive and hydrodynamic fluxes:

$$
\begin{aligned}
& \boldsymbol{q}^{\text {dif }}=-D_{e f f} \nabla C \\
& \boldsymbol{q}^{h y d}=C \boldsymbol{v} / S_{a}
\end{aligned}
$$

and will transfer from the mathematical surface $S$ to the corresponding "material surface" having a finite thickness and reflecting the physical properties of ground, walls, floor and ceiling of a house. The absolute values of diffusive fluxes crossing the material surface may be written in the form qdif $=D\left(C_{\text {out }}-C_{\text {in }}\right)$, where $D$ is a position-dependent diffusion coefficient for the material boundary. Then we split the general position-dependent diffusive flux $q$ dif for each of two separated zones of the house into ingoing and outgoing fluxes from the region labelled by index $i$ to the region labelled by index $j$. In a similar way, we specify the general position-dependent hydrodynamic flux $\boldsymbol{q}^{\text {hyd }}$ as ingoing and outgoing 
hydrodynamic fluxes. Using these specifications in eqns (A3), (A4) and replacing integration over $S$ by multiplication over relevant surface areas corresponding to the above specified spatially homogeneous parts of the general diffusive and hydrodynamic fluxes, one can easily obtain equations (36), (37) and (38), (39) of the main text which are used for calculating the concentration $C_{2}$ of toxic vapor inside the living space of a house. 


\section{FIGURE CAPTIONS}

Fig. 1. Schematic diagram of the detached house considered. Arrows indicate ingoing and outgoing fluxes of a chemical

Fig. 2 Two basic construction styles incorporating a subfloor void:

a) ground boundary, comprising hard core (1), blinding sand (2), and oversite concrete (3), with a suspended floor, comprising insulating layer (4) and overlapping timber bars (5);

b) ground boundary comprising hard core (1) and blinding sand (2), with a suspended floor comprising proprietary beam and block floor system (3), screed (4), insulation layer, a PVC damp-proof membrane, and wooden decking (5).

Airbricks (6) provide natural ventilation of the void for both constructions

Fig. 3. Equivalent electric scheme facilitating calculations of pressure distribution and air fluxes in a house with a subfloor void. See text for details.

Fig. 4. Initial bulk-soil concentration of benzene, $C_{b}(0)$, as a function of wind velocity $v$ for a house with a suspended timber floor. Different half-lives (years) for benzene in soil are labelled on curves

Fig. 5. Air flow rates in a void, $I_{1}$, in a living space, $I_{2}$, and from void to living space, $I_{12}$, as functions of wind velocity $v$ for a house with a suspended timber floor 
Fig. 6. Air exchange rates in a void, $E_{x 1}$, and in a living space, $E_{x 2}$, as functions of wind velocity $v$ for a house with a suspended timber floor

Fig. 7. Initial bulk-soil concentration of benzene, $C_{b}(0)$, as a function of wind velocity $v$ for a house with ideally air-tight floor. Different half-lives (years) for benzene in soil are labelled on curves

Fig. 8. Air flow rates in a void, $I_{1}$, in a living space, $I_{2}$, and from void to living space, $I_{12}$, as functions of wind velocity $v$ for a house with a suspended timber floor and with a window open on windward face.

Fig. 9. Air exchange rates in a void, $E_{x 1}$, and in a living space, $E_{x 2}$, as functions of wind velocity $v$ for a house with a suspended timber floor and with a window open on windward face.

Fig. 10. Initial bulk-soil concentration of benzene, $C_{b}(0)$, as a function of wind velocity $v$ for a house with a suspended timber floor and with a window open on windward face. Different half-lives (years) for benzene in soil are labelled on curves

Fig. 11. Initial bulk-soil concentration of benzene, $C_{b}(0)$, as a function of wind velocity $v$ for a house with a suspended beam and block floor with screed and without an oversite concrete. Different half-lives (years) for benzene in soil are labelled on curves 
Fig. 12. Initial bulk-soil concentration of benzene, $C_{b}(0)$, as a function of wind velocity $v$ for a house with a suspended timber floor and without oversite concrete. Different half-lives (years) for benzene in soil are labelled on curves

Fig. 13. Initial bulk-soil concentration of benzene, $C_{b}(0)$, as a function of wind velocity $v$ for a house with a suspended timber floor and without oversite concrete; a window is open on windward face. Different half-lives (years) for benzene in soil are labelled on curves

Fig. 14. Initial bulk-soil concentration of benzene, $C_{b}(0)$, as a function of wind velocity $v$ for a house with a suspended timber floor and without oversite concrete in the absence of subfloor void ventilation. Different half-lives (years) for benzene in soil are labelled on curves

Fig. 15. Initial bulk-soil concentration of benzene, $C_{b}(0)$, as a function of wind velocity $v$ for a house based on a tight concrete raft foundation. Different half-lives (years) for benzene in soil are labelled on curves

Fig. 16. Initial bulk-soil concentration of benzene, $C_{b}(0)$, as a function of wind velocity $v$ for a house with a suspended timber floor and oversite concrete in the presence of a cover system of thickness $1 \mathrm{~m}$. Different half-lives (years) for benzene in soil are labelled on curves 


\section{TABLE CAPTIONS}

Table 1. Data used in worked examples 


\section{Tables}

\begin{tabular}{|c|c|}
\hline Soil parameters & \\
\hline$\overline{\text { Specific gravity of dry soil: }}$ & $\gamma=1.6$ \\
\hline Air-filled porosity: & $S_{a}=0.2$ \\
\hline Water-filled porosity: & $S_{w}=0.1$ \\
\hline Organic carbon fraction: & $f_{O C}=0.01$ \\
\hline Benzene parameters & \\
\hline $\begin{array}{l}\text { Partition coefficient between soil organic carbon and water: } \\
\text { Dimensionless Henry's constant: }\end{array}$ & $\begin{array}{l}K_{Q C}=80 \mathrm{~cm}_{3} / \mathrm{g} \\
H^{1}=0.22\end{array}$ \\
\hline House parameters & \\
\hline Volume of living space: & $V_{2}=300 \mathrm{~m}^{3}$ \\
\hline Height of subfloor void: & $H_{1}=0.2 \mathrm{~m}$ \\
\hline Height of living space: & $H_{2}=5.0 \mathrm{~m}$ \\
\hline Perimeter of house: & $p=31 \mathrm{~m}$ \\
\hline Surface area of internal windows and doors: & $A_{w d}=20 m_{2}$ \\
\hline Thickness of hard-core layer & $0.1 \mathrm{~m}$ \\
\hline Thickness of blinding sand & $0.05 \mathrm{~m}$ \\
\hline Thickness of an oversite concrete & $0.1 \mathrm{~m}$ \\
\hline Thickness of timber floor & $0.03 \mathrm{~m}$ \\
\hline Thickness of screed & $0.02 \mathrm{~m}$ \\
\hline Thickness of floor insulating layer & $0.05 \mathrm{~m}$ \\
\hline Thickness of brick layer in walls & $0.1 \mathrm{~m}$ \\
\hline Thickness of lightweight block layer in walls & $0.1 \mathrm{~m}$ \\
\hline Thickness of insulating layer in walls & $0.055 \mathrm{~m}$ \\
\hline Thickness of surface coating on walls & $0.001 \mathrm{~m}$ \\
\hline Thickness of ceiling plasterboard & $0.0125 \mathrm{~m}$ \\
\hline Thickness of roof insulating layer & $0.1 \mathrm{~m}$ \\
\hline Thickness of ceiling surface coating & $0.001 \mathrm{~m}$ \\
\hline Building material properties & \\
\hline$\overline{\text { Air-filled porosity of hardcore }}$ & $25 \%$ \\
\hline Total porosity of hardcore & $50 \%$ \\
\hline Air-filled porosity of blinding sand & $50 \%$ \\
\hline Total porosity of blinding sand & $50 \%$ \\
\hline Air-filled porosity of concrete & $3.4 \%$ \\
\hline Total porosity of concrete & $6.8 \%$ \\
\hline Air-filled porosity of timber & $20 \%$ \\
\hline Total porosity of timber & $20 \%$ \\
\hline Air-filled porosity of screed & $6.8 \%$ \\
\hline Total porosity of screed & $6.8 \%$ \\
\hline Air-filled porosity of wall and roof insulating layer & $90 \%$ \\
\hline Total porosity of wall and roof insulating layer & $90 \%$ \\
\hline Air-filled porosity of brick & $25 \%$ \\
\hline Total porosity of brick & $50 \%$ \\
\hline Air-filled porosity of plasterboard & $6.8 \%$ \\
\hline Total porosity of plasterboard & $6.8 \%$ \\
\hline
\end{tabular}

Table 1. Data used in worked examples 
Figures

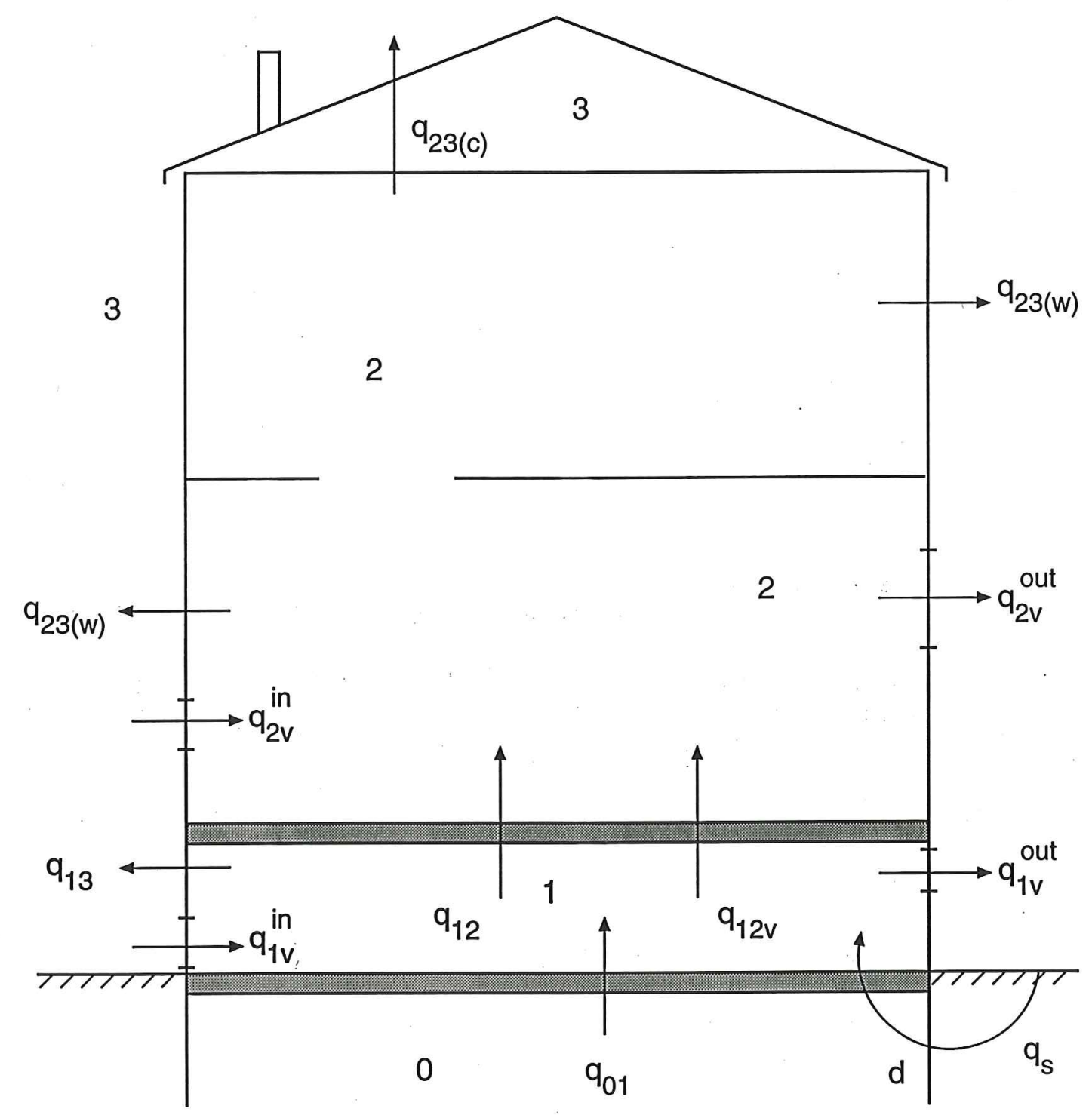

Fig. 1 

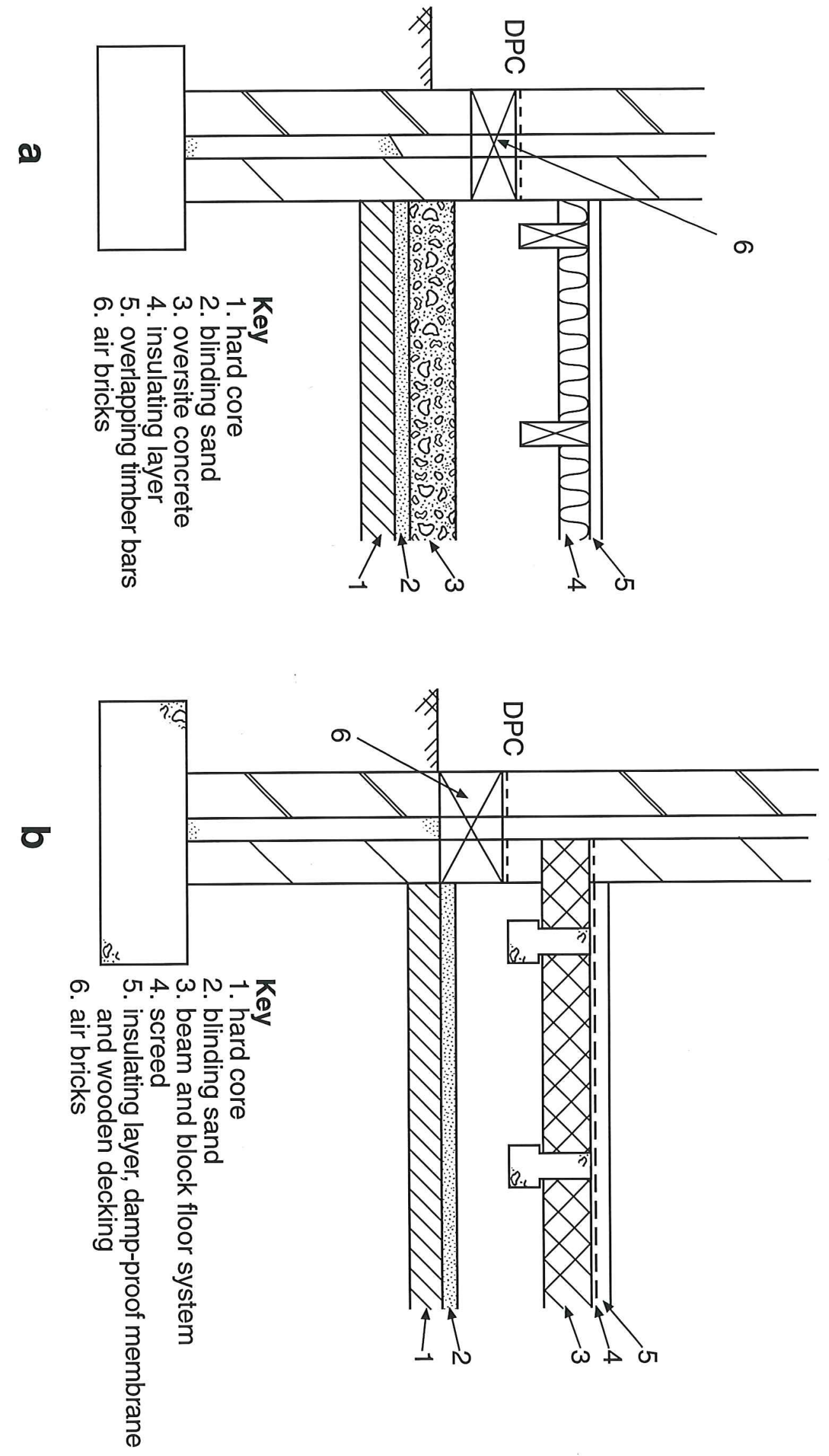


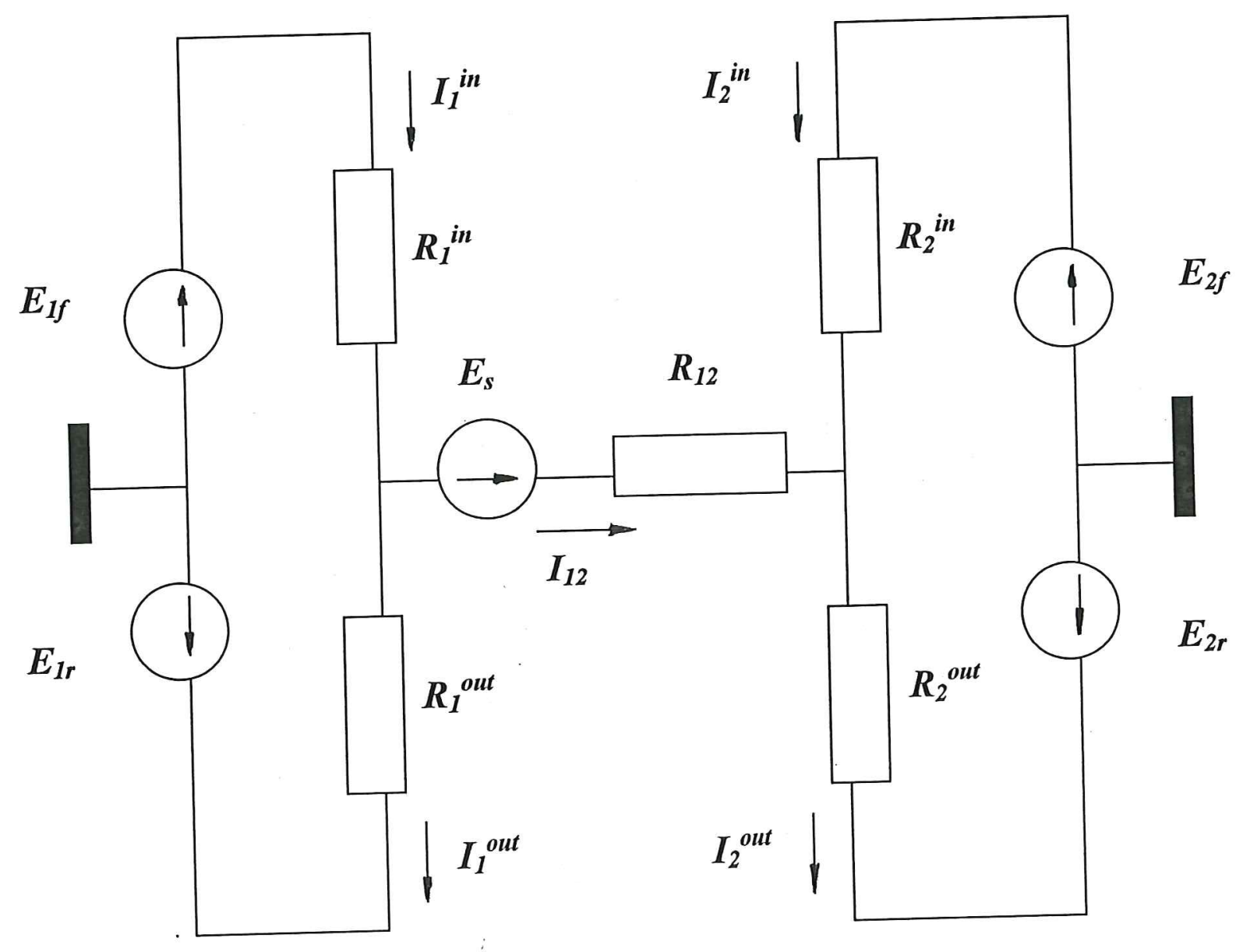

Fig. 3 


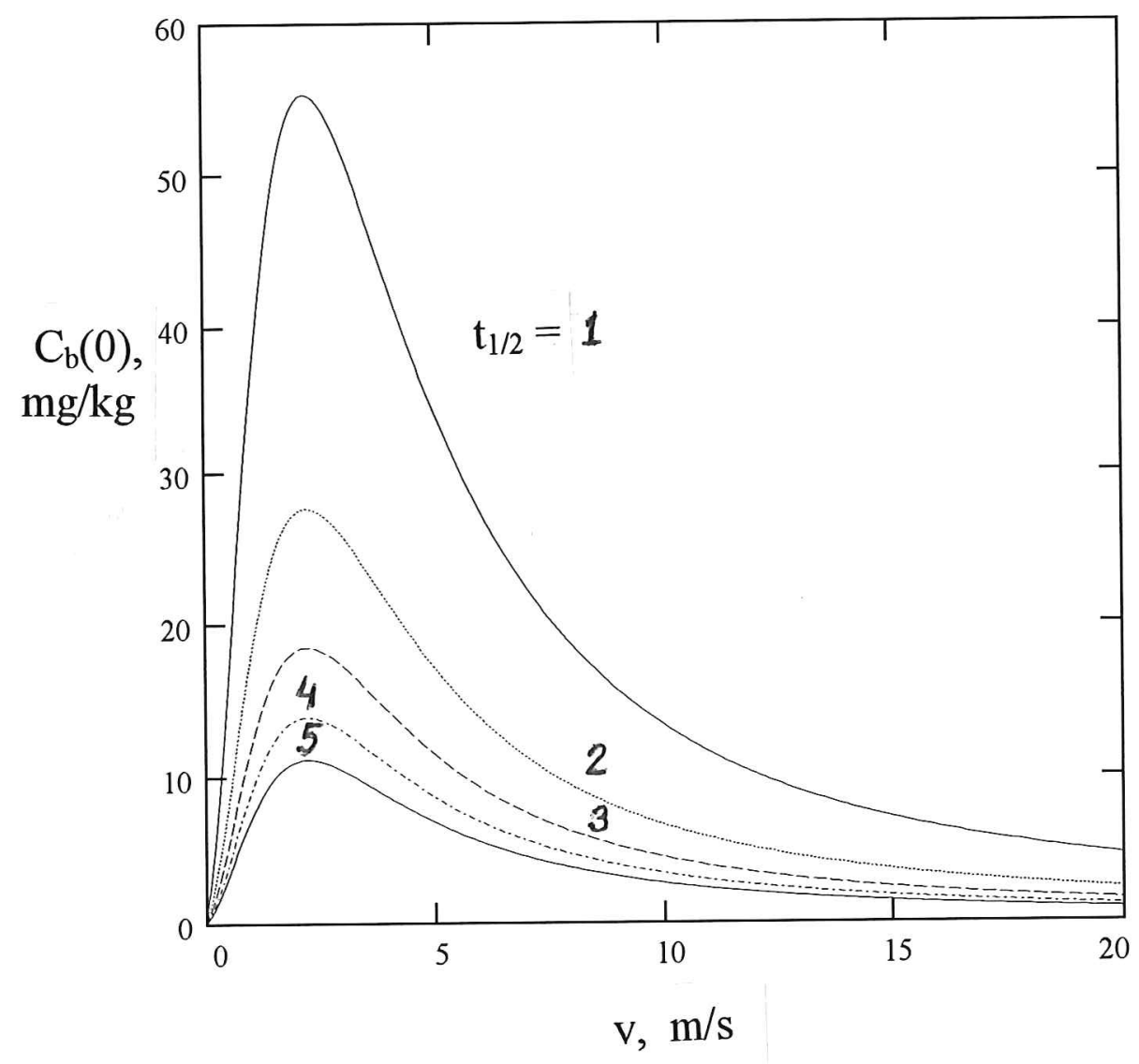

Fig. 4 


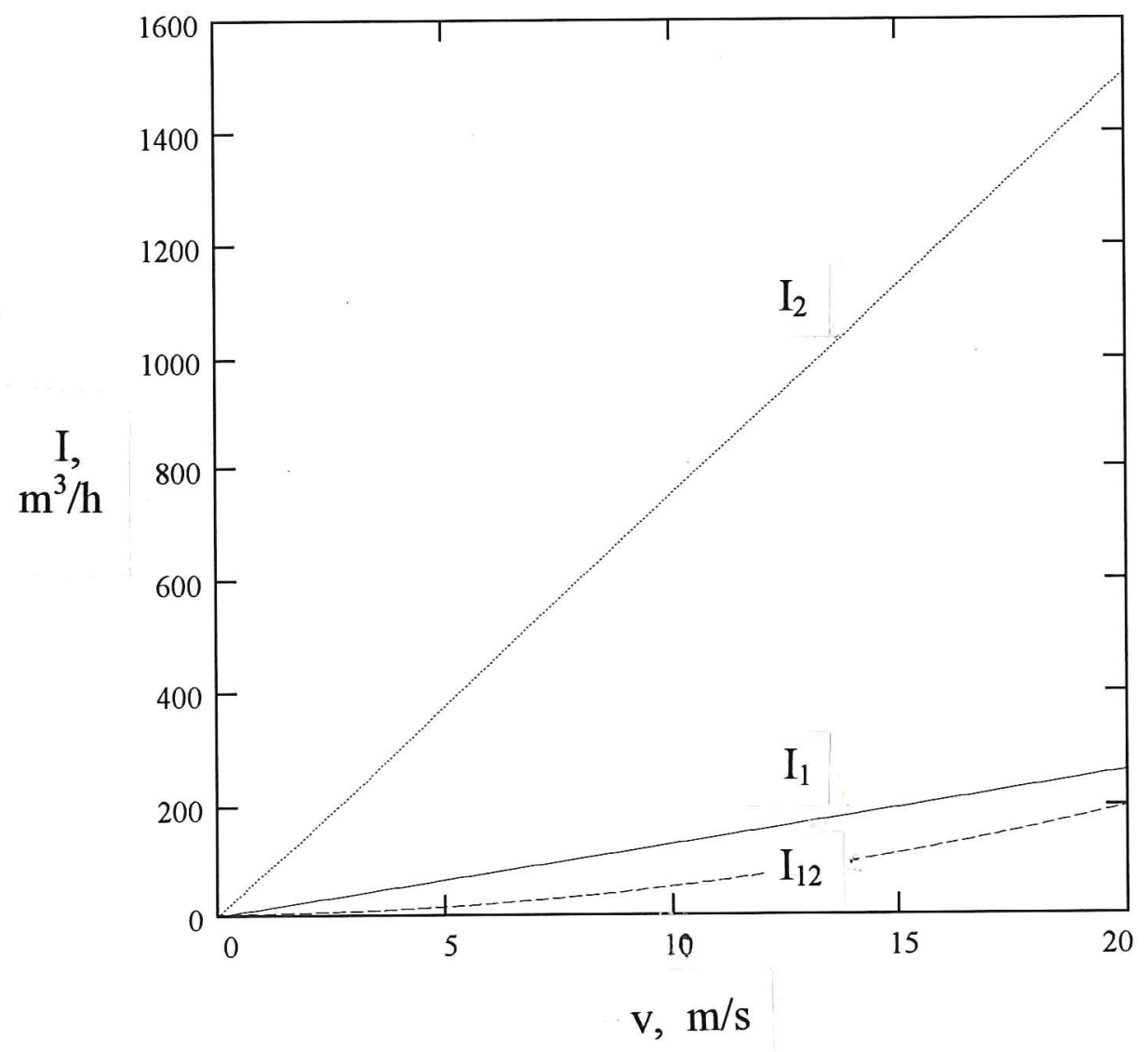

Fig. 5 


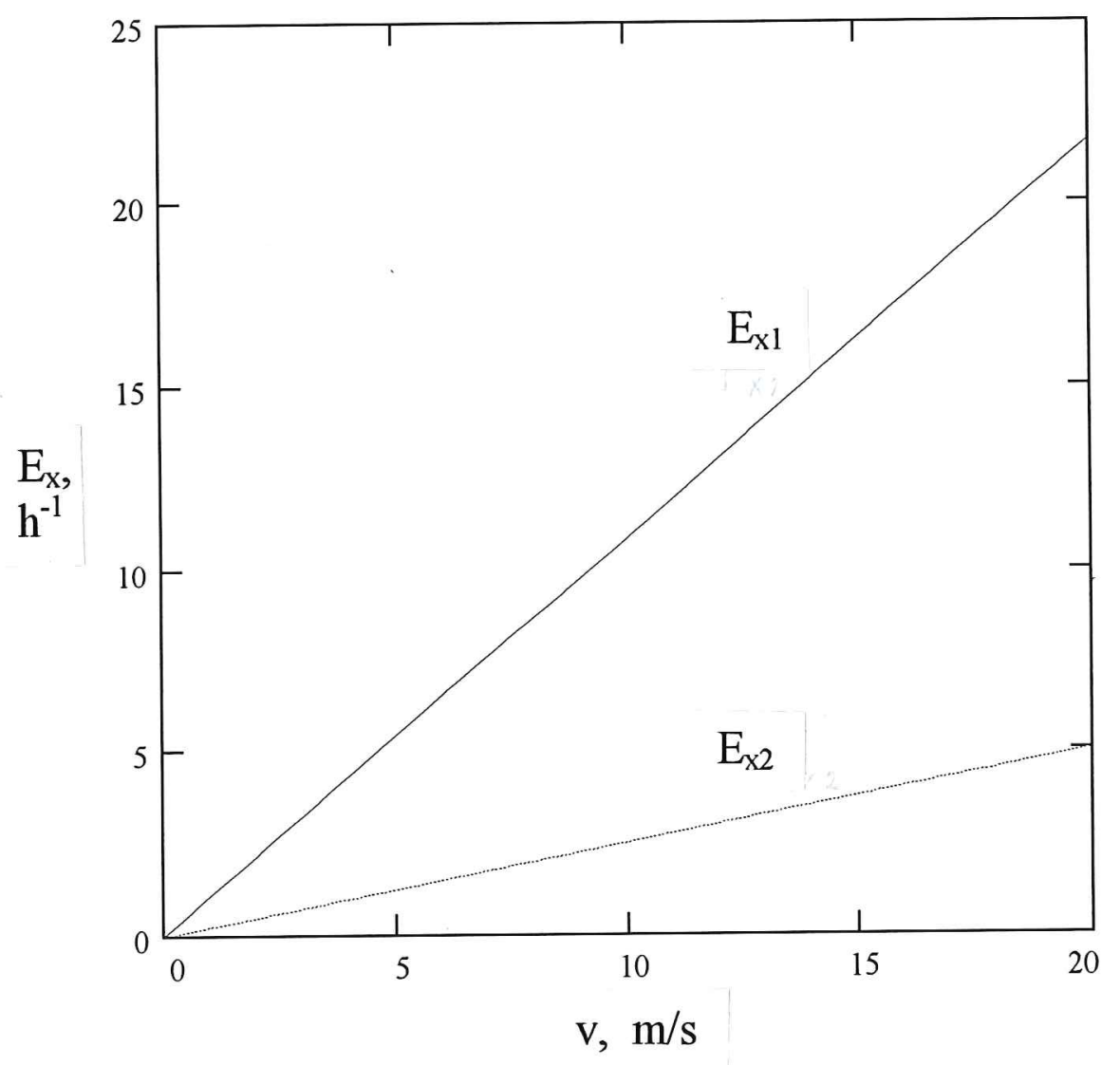

Fig. 6 


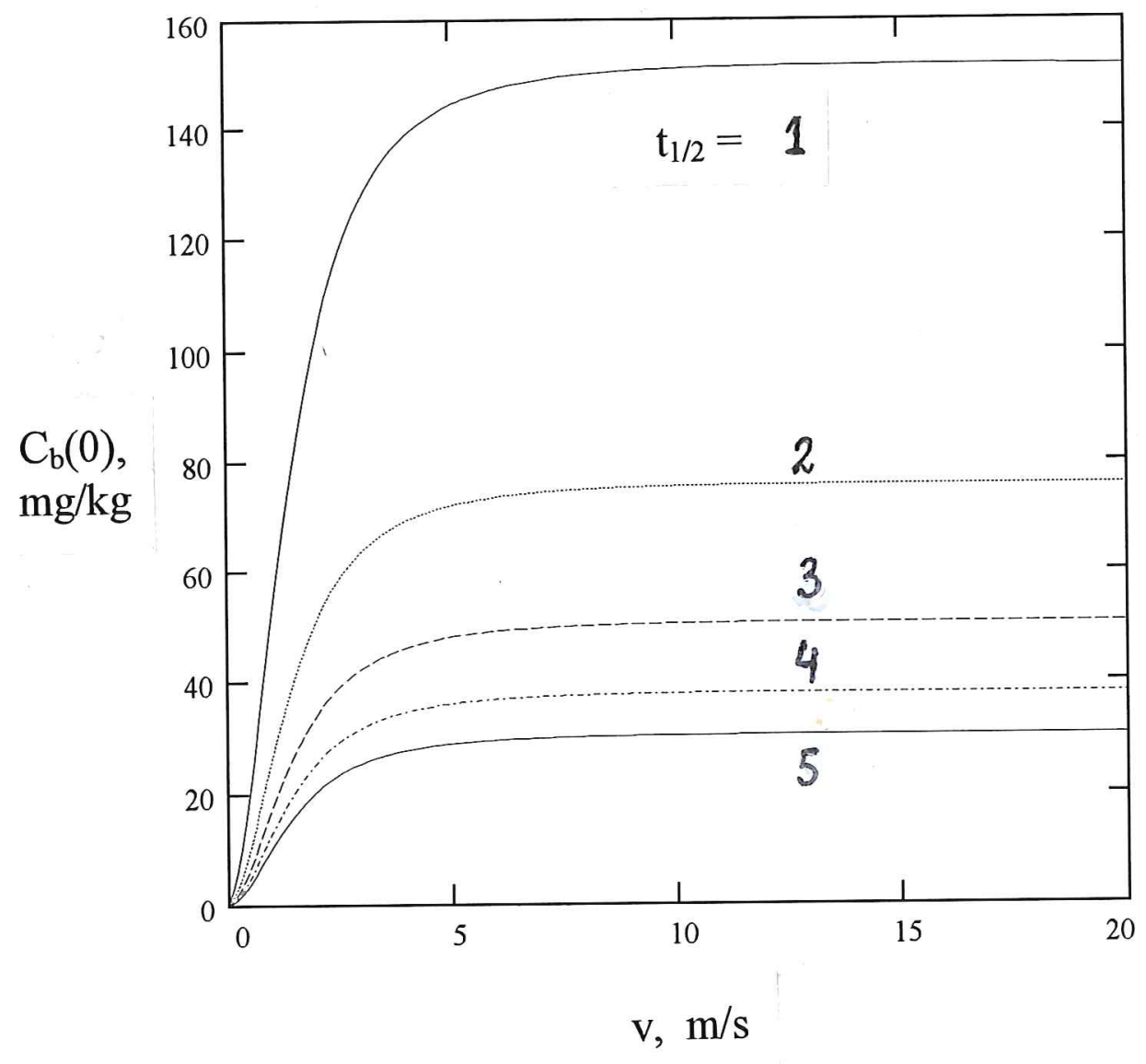

Fig. 7 


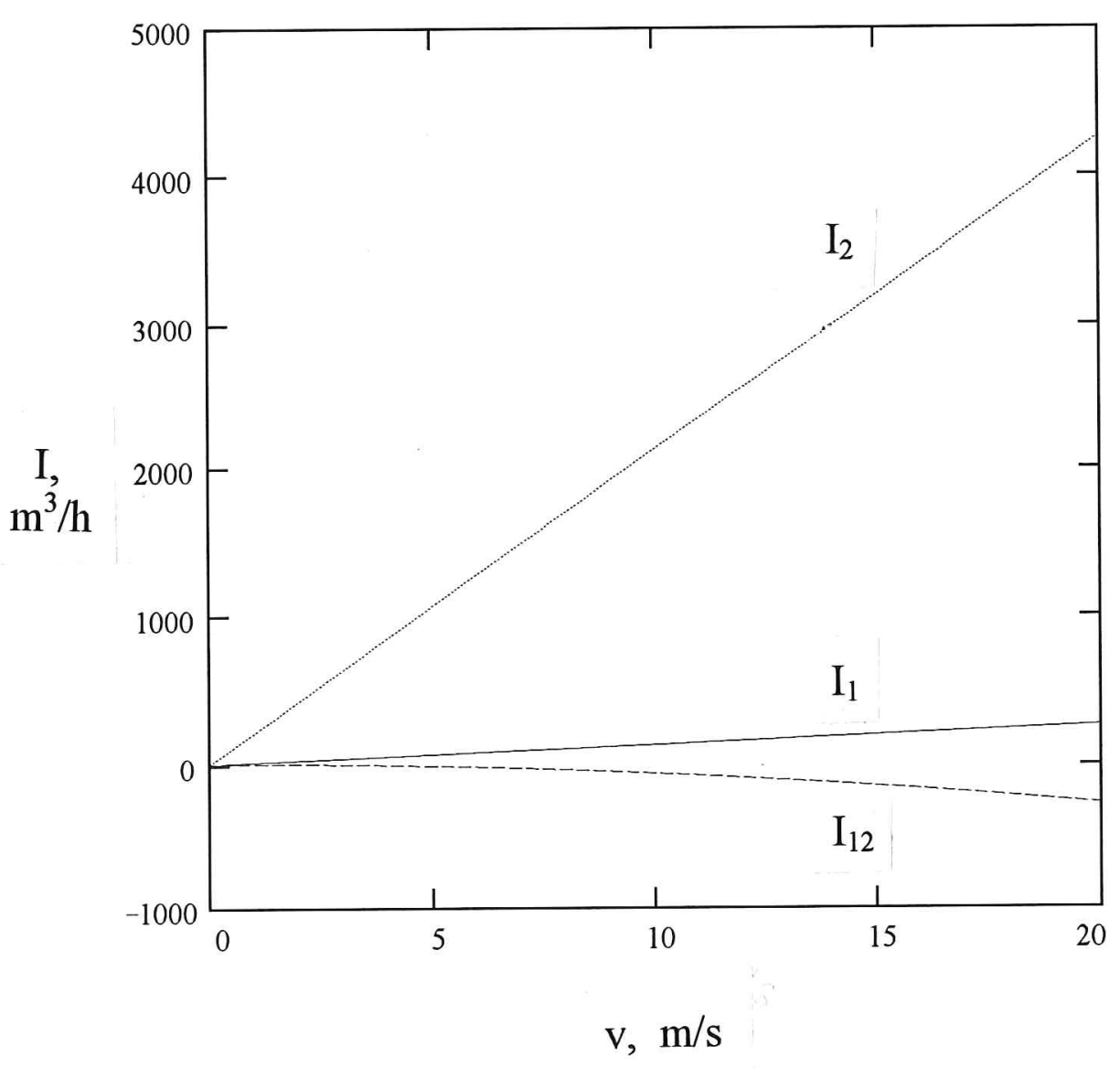

Fig. 8 


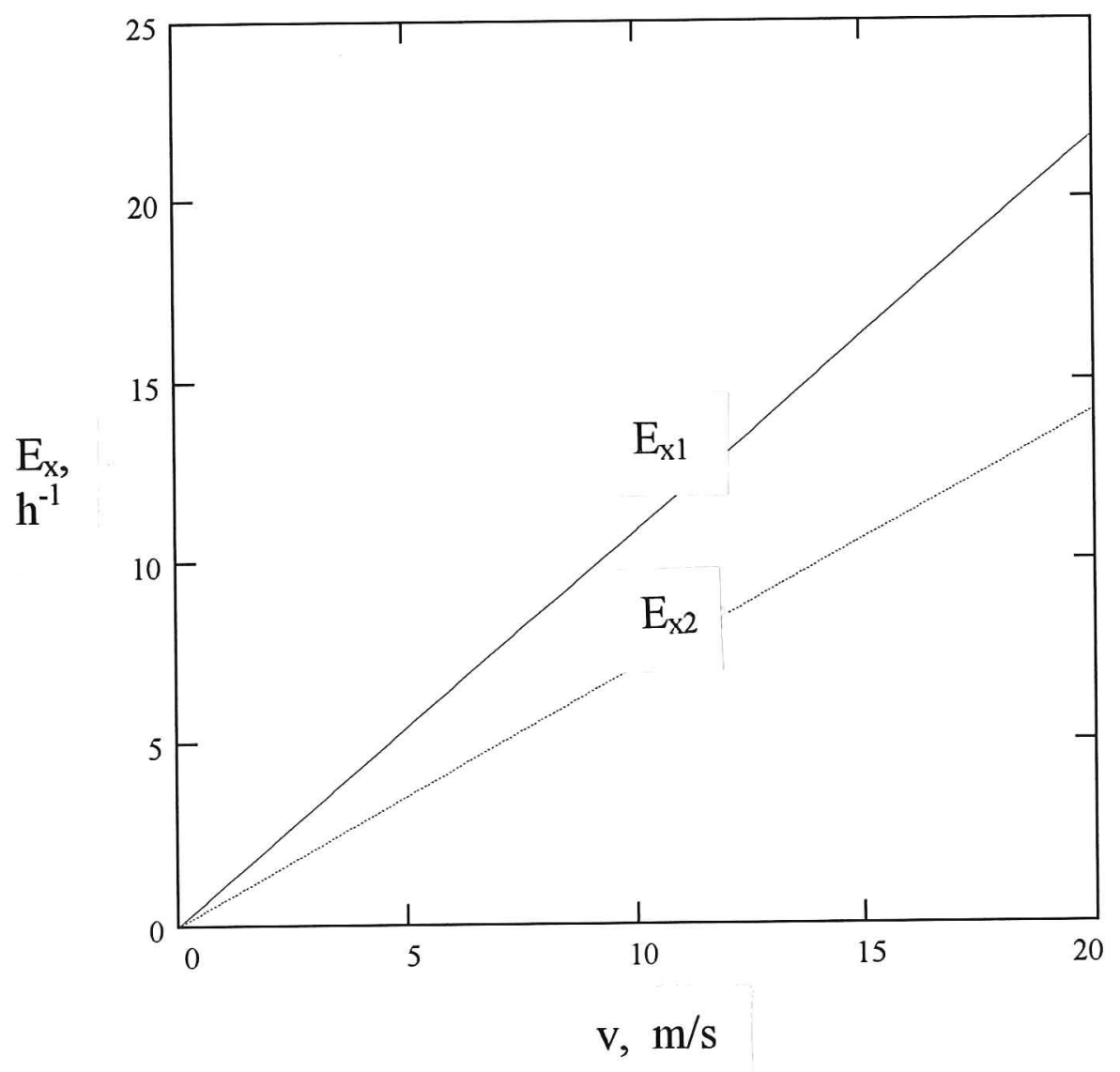

Fig. 9 


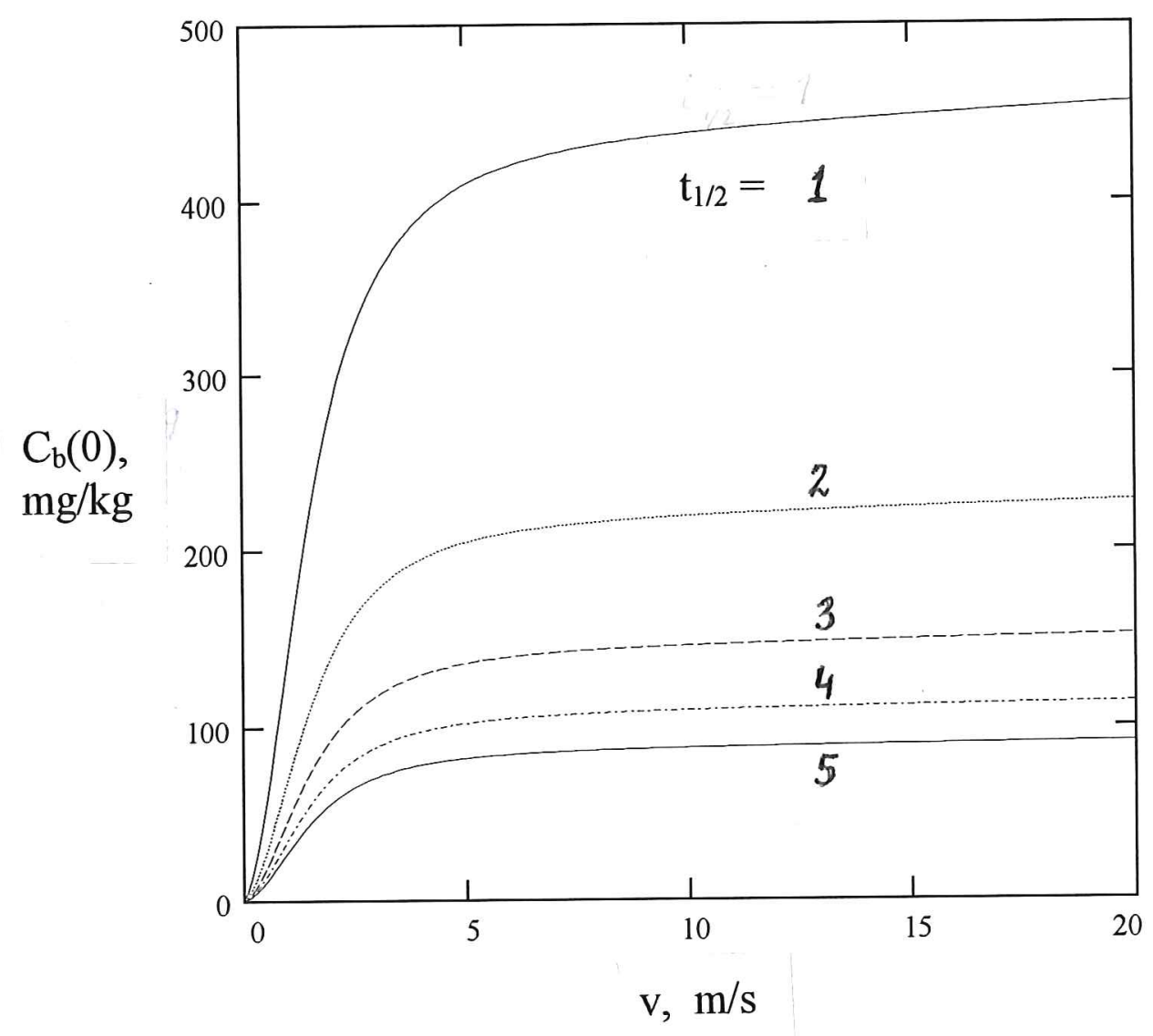

$$
\text { Fig. } 10
$$




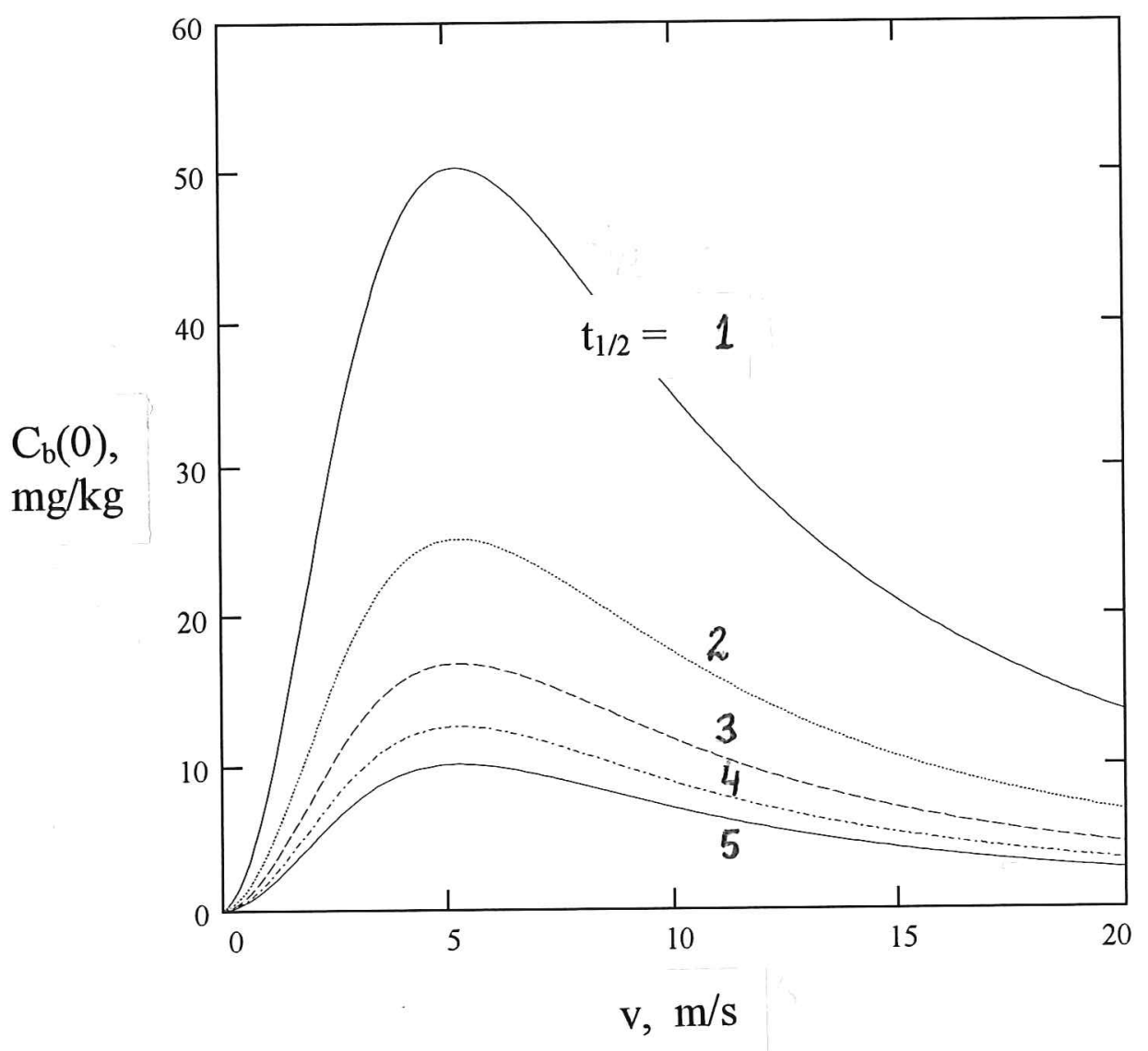

Fig. 11 


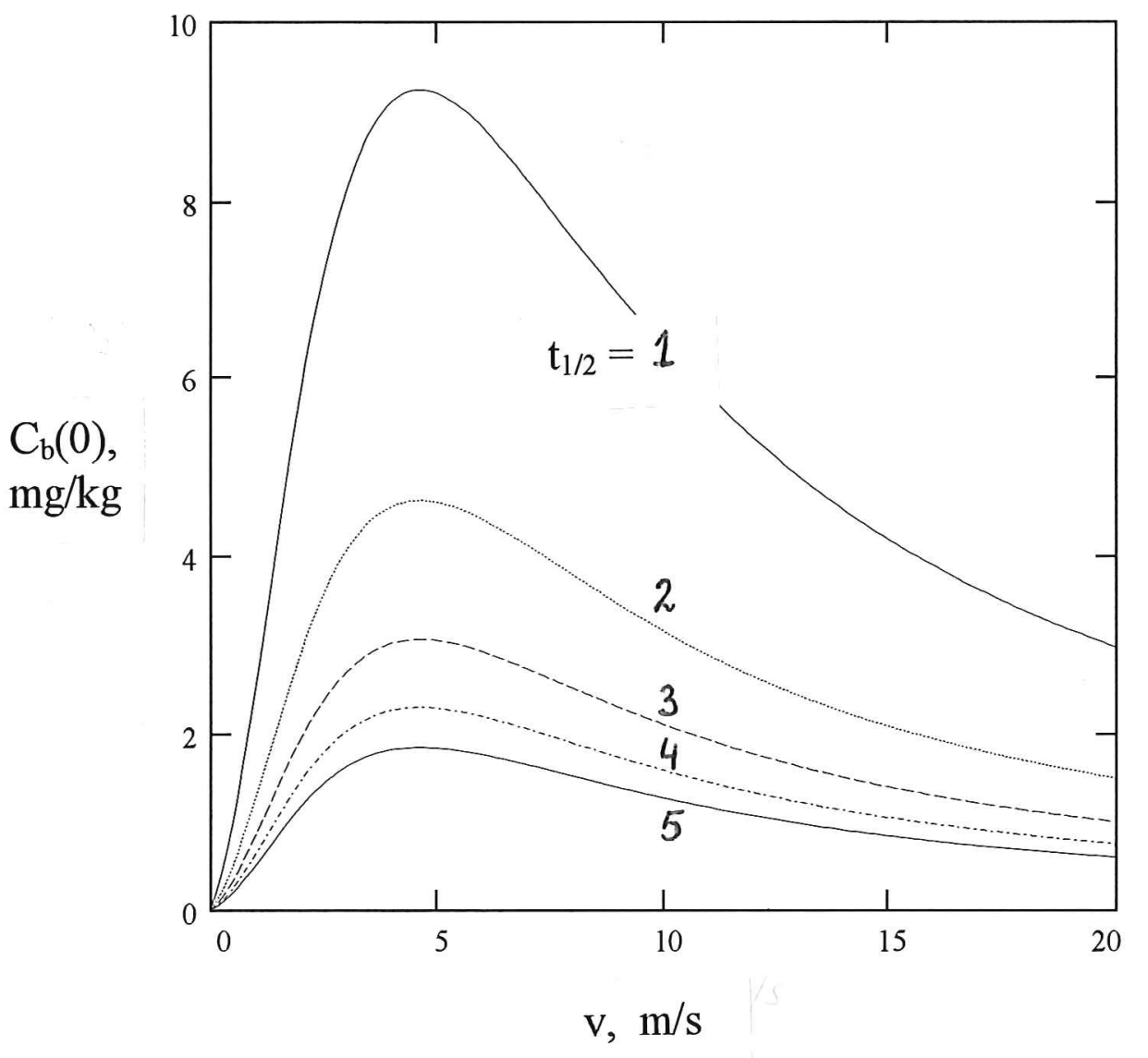

Fig. 12 


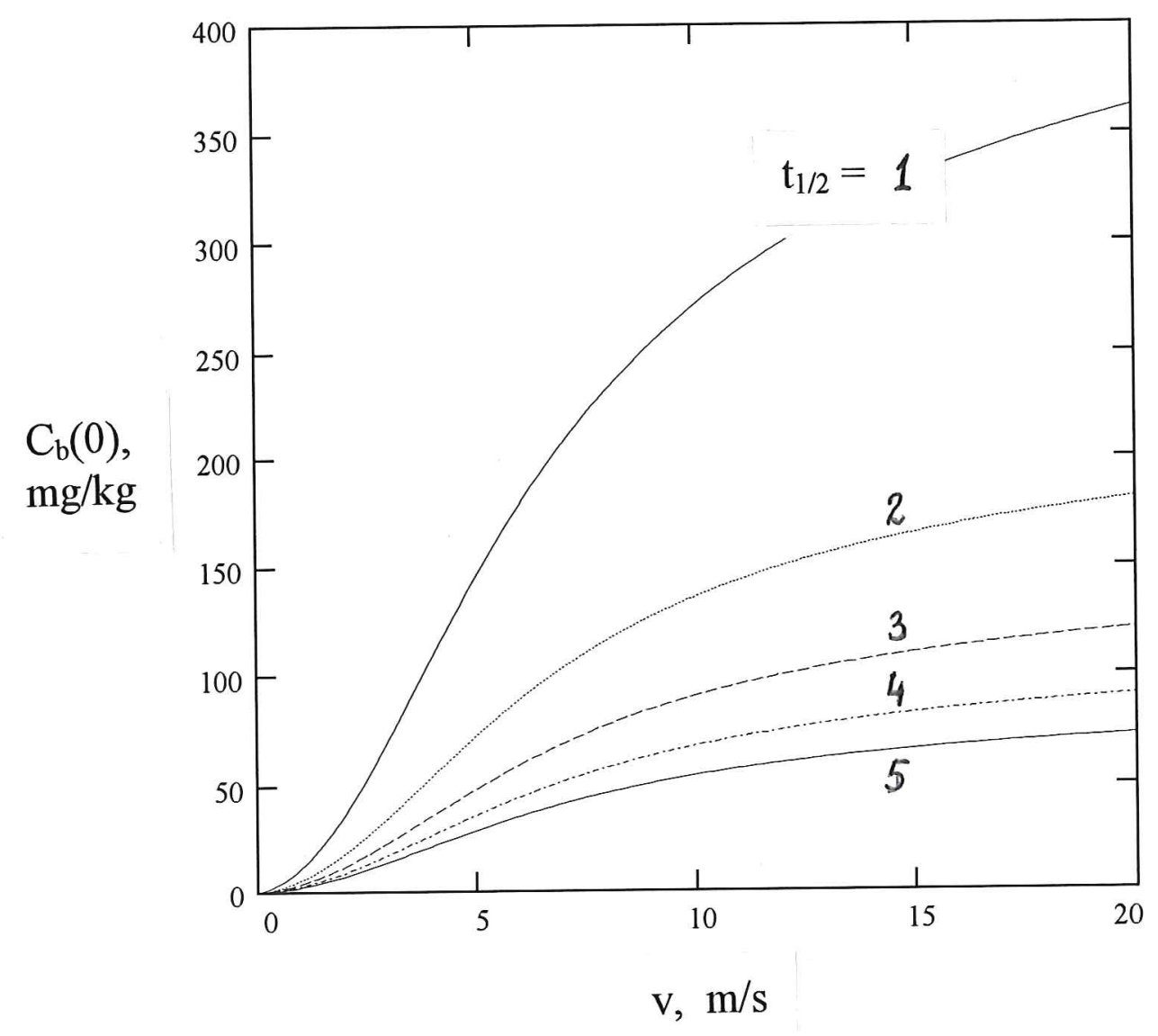

Fig. 13 


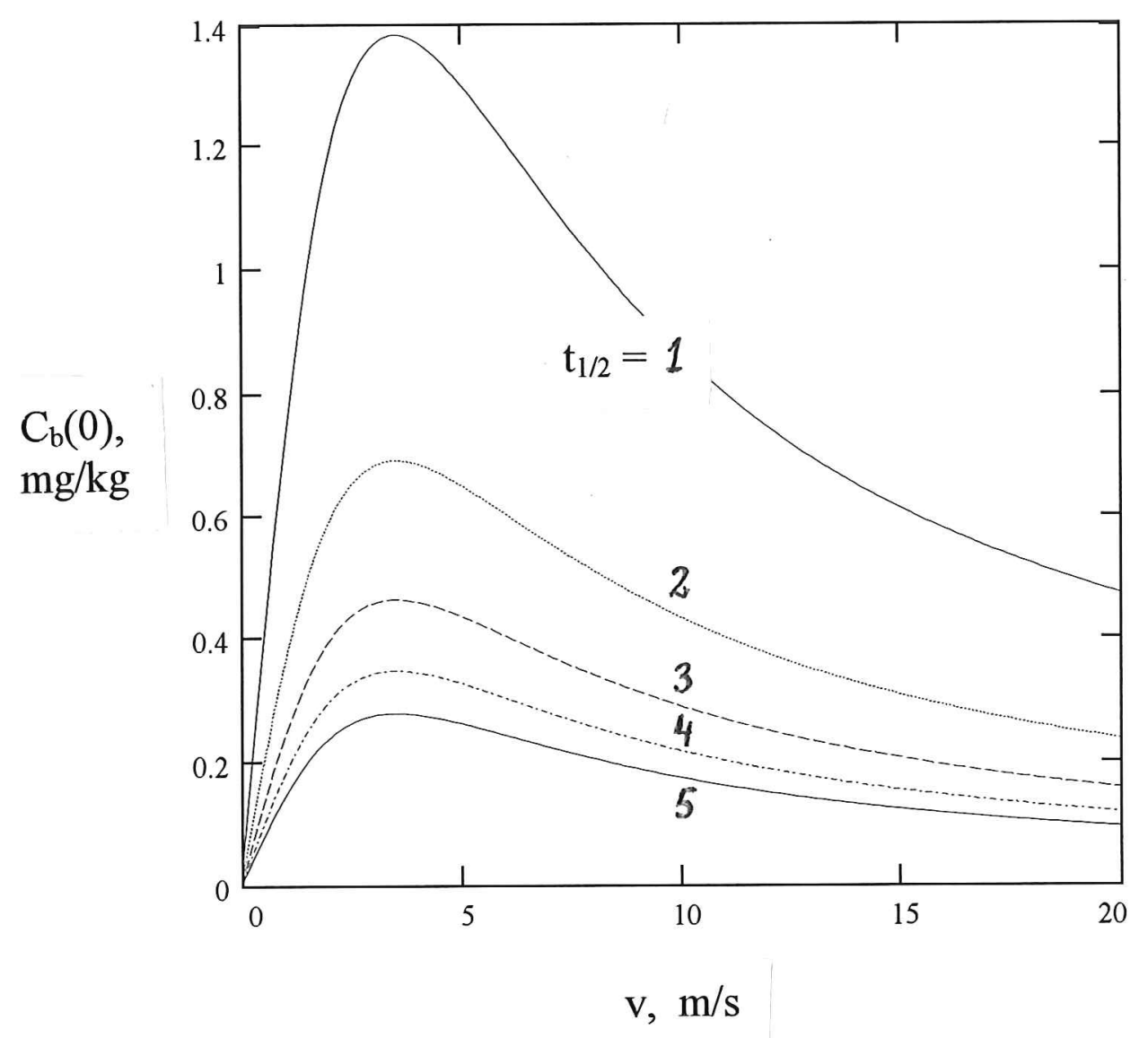

Fig. 14 


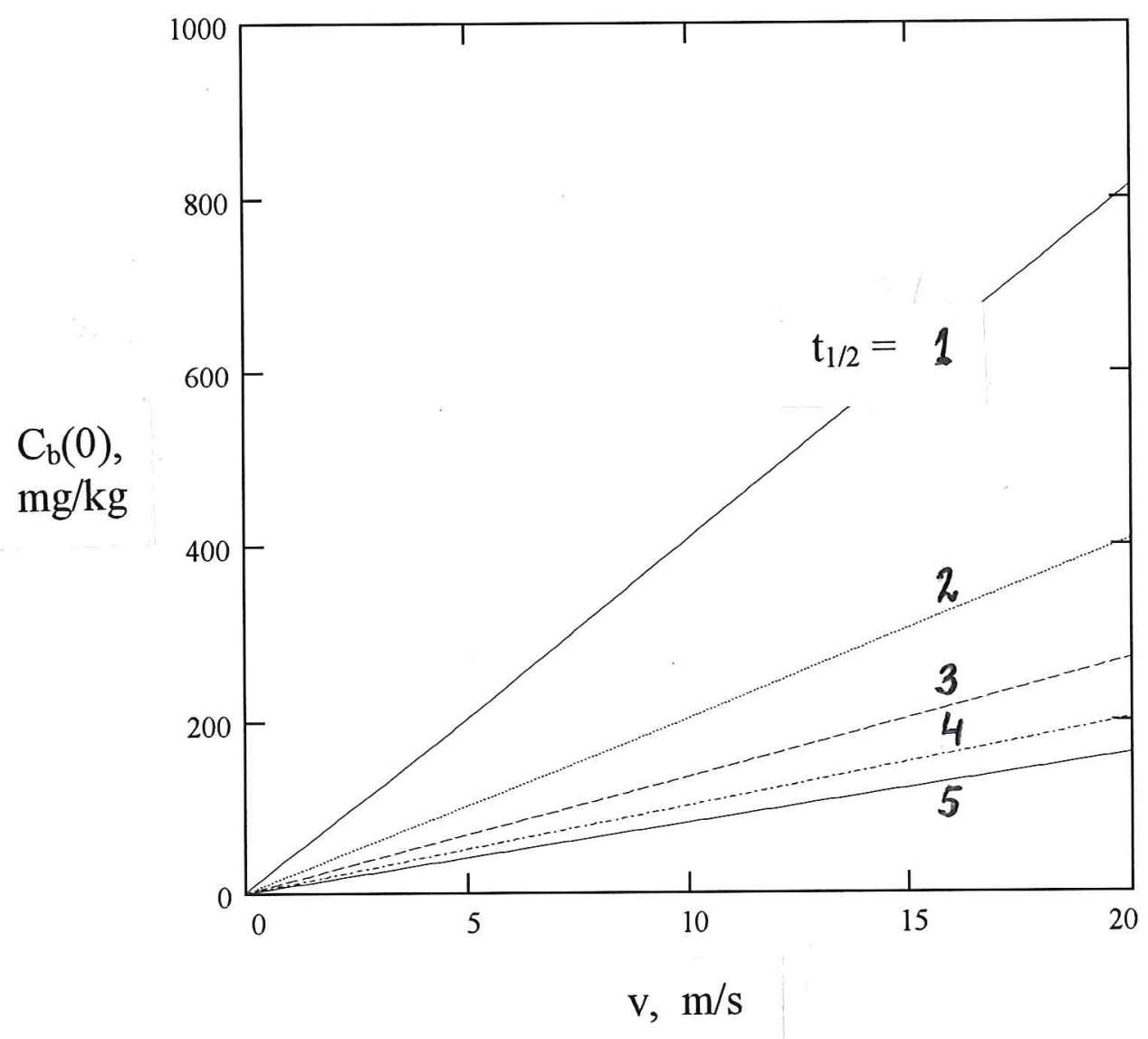

Fig. 15 


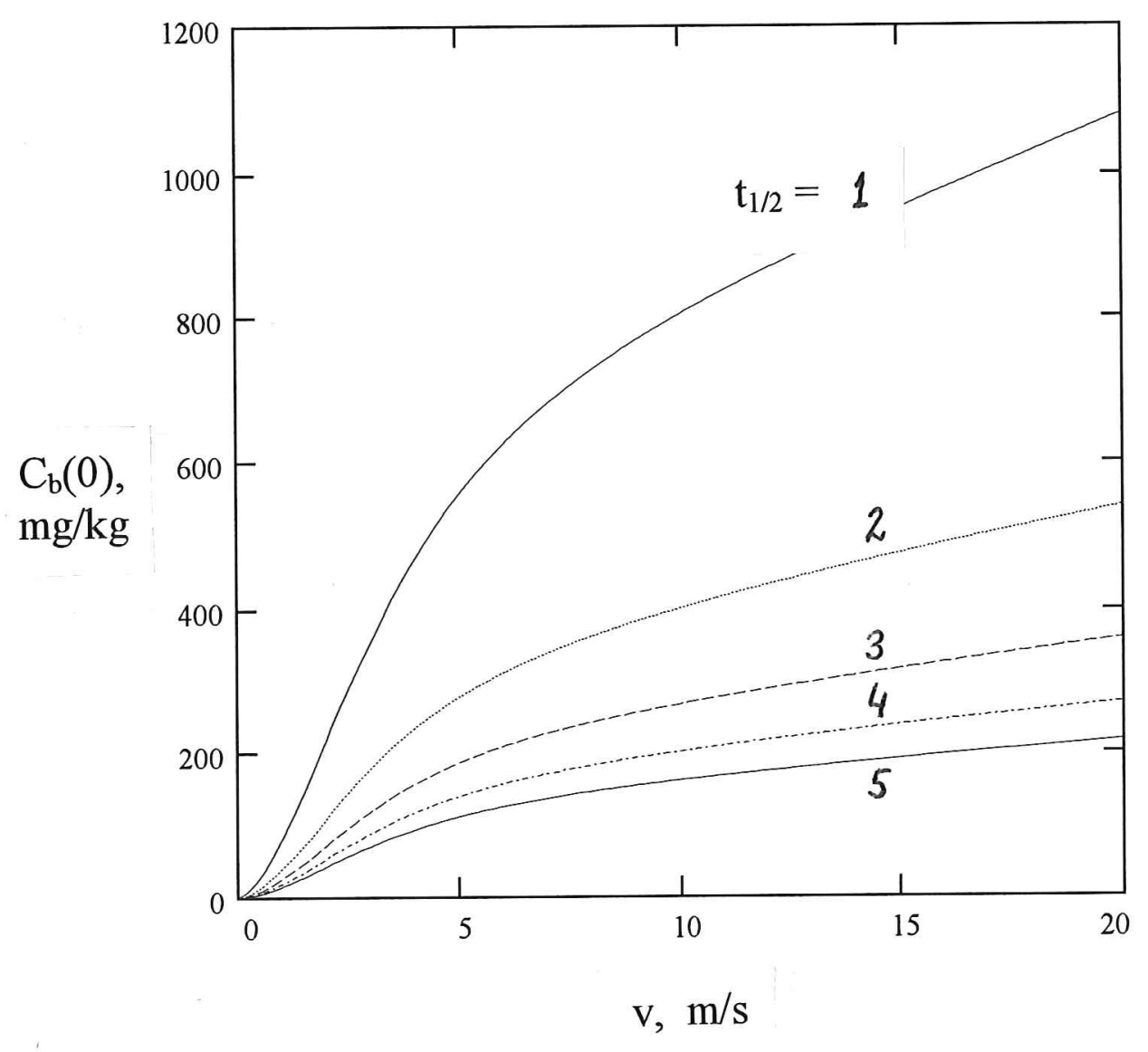

Fig. 16 